\title{
Why and How Investors Use ESG Information: Evidence from a Global Survey
}

\section{Citation}

Amel-Zadeh, Amir, and George Serafeim. "Why and How Investors Use ESG Information:

Evidence from a Global Survey." Harvard Business School Working Paper, No. 17-079, February 2017.

\section{Permanent link}

http://nrs.harvard.edu/urn-3:HUL.InstRepos:30838135

\section{Terms of Use}

This article was downloaded from Harvard University's DASH repository, and is made available under the terms and conditions applicable to Open Access Policy Articles, as set forth at http:// nrs.harvard.edu/urn-3:HUL.InstRepos:dash.current.terms-of-use\#OAP

\section{Share Your Story}

The Harvard community has made this article openly available.

Please share how this access benefits you. Submit a story.

Accessibility 


\section{Why and How Investors Use ESG Information: Evidence from a Global Survey}

Amir Amel-Zadeh

George Serafeim

Working Paper 17-079 


\title{
Why and How Investors Use ESG Information: Evidence from a Global Survey
}

\author{
Amir Amel-Zadeh \\ Said Business School, University of Oxford \\ George Serafeim \\ Harvard Business School
}

Working Paper 17-079 


\title{
Why and How Investors Use ESG Information: Evidence from a Global Survey
}

\author{
Amir Amel-Zadeh* \\ Said Business School, University of Oxford \\ George Serafeim \\ Harvard Business School
}

February 2017

\begin{abstract}
Using survey data from a sample of senior investment professionals from mainstream (i.e. not SRI funds) investment organizations we provide insights into why and how investors use reported environmental, social and governance (ESG) information. The primary reason survey respondents consider ESG information in investment decisions is because they consider it financially material to investment performance. ESG information is perceived to provide information primarily about risk rather than a company's competitive positioning. There is no one size fits all, with the financial materiality of different ESG issues varying across sectors. Lack of comparability due to the lack of reporting standards is the primary impediment to the use of ESG information. Most frequently, the information is used to screen companies with the most often used method being negative screening. However, negative screening is perceived as the least investment beneficial while full integration into stock valuation and positive screening considered more beneficial. Respondents expect negative screening to be used less in the future, while positive screening and active ownership to be used more.
\end{abstract}

Keywords: ESG, sustainability, investment performance, nonfinancial, disclosure

\footnotetext{
* Corresponding author: Park End Street, Oxford OX1 1HP, UK. Email: amir.amelzadeh@sbs.ox.ac.uk. We appreciate comments and suggestions from Elroy Dimson, Bob Eccles, Andrew Karolyi, Xi Li, Harry Markowitz, Geoff Meeks, and Geoff Whittington, and thank participants at the $3^{\text {rd }}$ Stranded Assets Forum 2015, and the 2015 and 2016 Conference on Long-Term Investing at the Newton Centre for Endowment Asset Management for helpful discussions. Amir Amel-Zadeh would also like to thank Bank of New York Mellon, IPREO and Institutional Investor Research Group for support with survey distribution and administration. Amir Amel-Zadeh recognizes support from the Newton Centre for Endowment Asset Management, University of Cambridge and Bank of New York Mellon. George Serafeim recognizes support from the Division of Faculty Research and Development of Harvard Business School. Contact information for George Serafeim: Email: gserafeim@ @bs.edu. Harvard Business School, 381 Morgan Hall, Boston MA 02127, USA.
} 


\section{Introduction}

In the past twenty-five years, the world has seen an exponential growth in the number of companies measuring and reporting environmental (i.e. carbon emissions, water consumption, waste generation, etc.), social (i.e. employee, product, customer related, etc.), and governance (i.e. political lobbying, anticorruption board diversity, etc.) data, collectively ESG data. While fewer than 20 companies disclosed ESG data in the early 1990s, the number of companies issuing sustainability or integrated reports had increased to nearly 9,000 by 2016 .

Investor interest in ESG data also grew rapidly. Signatories to the UN Principles for Responsible Investment (PRI), launched in 2006, committed to incorporating ESG issues into their investment analysis and ownership policies and practices. As of 2016, the principles had about 1,400 signatories with total assets under management of about $\$ 60$ trillion. ${ }^{1}$ As a further sign of the institutionalization of ESG data, Bloomberg terminals integrated ESG data in 2010, dramatically increasing the diffusion of ESG information. As of 2016, more than 100 rating agencies provided ESG data, including large data providers such as Thomson Reuters and Morgan Stanley Capital International (MSCI).

Recent studies have documented that ESG information is associated with numerous economically meaningful effects. Specifically, ESG disclosures are associated with lower capital constraints (Cheng, Ioannou and Serafeim 2014), cost of capital (Dhaliwal et. al 2011), analyst forecast errors (Dhaliwal et. al 2012), and stock price movements around mandatory ESG disclosure regulations (Grewal, Riedl and Serafeim 2017). Moreover, industry-specific classifications of financial materiality of ESG information identify ESG information that is value relevant and predictive of firms' future financial performance (Khan, Yoon and Serafeim 2016) and are associated with less stock price

\footnotetext{
${ }^{1}$ United Nations Principles for Responsible Investment, http://www.unpri.org/signatories/signatories/.
} 
synchronicity whereby prices are moving more because of firm-specific information (Grewal, Hauptman and Serafeim 2017). ${ }^{2}$

While these studies document significant economic effects, we still lack a deeper understanding of why and how investors use ESG information as well as the challenges in using this information. To enhance our understanding and complement archival research, we administered a survey with the collaboration of a global financial institution (i.e. BNY Mellon). We received 413 responses from senior investment professionals with an average response rate across the questions in the survey of $9 \%$. This is in line with other surveys that have collected responses from CFOs and obtained rates of 9, 8.4 and 5.4\% (Graham and Harvey 2001; Graham, Harvey and Rajgopal 2005; Dichev et al. 2013). On a value weighted basis, our respondents comprise $43 \%$ percent of the global institutional assets under management (AUM), as respondents have $\$ 31$ trillion in AUM. Only 8\% of them have the title of ESG investment professional with the vast majority having the title of portfolio manager. Moreover, the vast majority of our respondents had no or only a small allocation in ESGspecific funds. Almost 70\% of the sample has less than 10\% of the assets in ESG-specific funds. Therefore, in contrast to many surveys in the ESG space, our sample reflects the views of largely mainstream investment professionals.

Although data collected through survey instruments potentially suffer from several problems (response bias, selection bias, attribution bias), surveys offer a way to collect data and provide insights in questions that cannot be addressed at that point in time by archival data. As Dichev et al. (2013) suggest, "Surveys... allow researchers to (i) discover institutional factors that impact practitioners' decisions in unexpected ways and (ii) ask key decision makers directed questions about their behavior

\footnotetext{
2 These studies use the materiality definition adopted by the Sustainability Accounting Standards Board, and defined by the U.S. Supreme Court: information is material if there is "a substantial likelihood that the disclosure of the omitted fact would have been viewed by the reasonable investor as having significantly altered the 'total mix' of information made available."
} 
as opposed to inferring intent from statistical associations between proxy variables surrogating for such intent." Therefore, our intention is to generate insights that provide directions for future archival research.

Our key findings fall in six main categories. First, we address the question of what motivates investors to use ESG data. The clear majority of respondents $(82 \%)$ suggest that they use ESG information because it is financially material to investment performance. We find a higher proportion of US compared to European investors $(22 \%$ vs $4 \%$ ) thinking that the information is not material for investment purposes and that using the information would violate their fiduciary duty ( $22 \%$ vs $8 \%$ ). The latter finding is interesting in the context of recent guidance by the US Department of Labor that clarifies that incorporation of ESG information in investment decisions is not inconsistent with fiduciary duties. A significant percentage of the sample considers the information also from an active ownership viewpoint (Dimson et al. 2015). They believe that engagement with companies can bring change in the corporate sector and address ESG issues, but again this belief is much more widespread among European investors. An equal percentage of the sample considers ESG information because of growing client demand or formal client mandates. This is the case for larger asset managers consistent with these managers being reactive to the need to incorporate ESG information. A lower percentage of respondents considers such information because they see it as their ethical responsibility, with European investors being more likely to consider this an ethical responsibility. Overall, we find strong evidence that use of ESG information has primarily financial rather than ethical motives in our sample.

The second set of results relates to why ESG information is material for investment decisions. Respondents believe that this information is primarily relevant for assessing a company's reputational, legal and regulatory risk. The second reason relates to better ESG performance serving as a proxy for management quality. Respondents are less likely to think that ESG information reflects a company's 
competitive positioning. We argue that investors seeing ESG information as providing information on risks but not competitive positioning could be traced in the origins of corporate social responsibility (CSR) or sustainability reporting as a corporate accountability mechanism. The goal was to mitigate negative externalities imposed on different stakeholders through increases in transparency that could enable stakeholders to better hold corporations accountable for their impacts. Still the state of ESG data does not allow for an assessment of competitive positioning that generates shared value (Porter and Kramer 2011).

The third set of results relates to which ESG issues are financially material for investment decisions. Respondents view anticorruption, leadership and board, climate change, and energy/fuel management related information as most material. Among these, European investors consider relatively more customer and employee related information as material compared US investors. However, more importantly, the financial materiality of different ESG issues varies systematically across sectors. For example, climate change is material for the energy sector, impact of business activities on local communities for the basic materials sector, ESG policies and practices of companies' suppliers for the consumer and retail sector, and a company's governance policies for the financial sector.

The fourth set of results relates to barriers in ESG data integration in the investment decision process. Comparability, timeliness and reliability are all key qualitative characteristics that make financial information decision useful as identified in both US Generally Accepted Accounting Principles (GAAP) and International Financial Reporting Standards (IFRS). The biggest challenge to using ESG information for investment decision making relates to the lack of comparability of reported information across firms. Respondents identify the lack of reporting standards as a major source inhibiting the comparability of reported information. Cost of gathering and analyzing ESG data is also identified as a major barrier. A large number of data providers have expanded their capacity and capabilities to collect and distribute the data to the investment community as a response. 
Quantification of ESG information is also identified as a major challenge, followed by lack of timeliness and concerns about the reliability of reported information.

The fifth set of results focuses on how the information is used by investors in our sample. We find that, at the firm-level, an equal number of investors use it to engage with firms or as an input into the valuation model. A lower percentage uses it as an input in estimating a firm's idiosyncratic or systematic risk. A significantly higher percentage of the respondents believe that stocks with good ESG performance have lower systematic risk, attract a positive risk premium or are underpriced by the market compared to those that believe that these stocks have higher systematic risk, attract a negative risk premium or are overpriced by the market. At the portfolio-level we find that most respondents use the information to define the investment universe through a screening process. In terms of screening, still the most frequently used approach is negative screening. Specifically, excluding sin stocks followed by excluding firms with the lowest ESG performance. Positive screening methods, either across industries or within an industry (i.e. best-in-class) are still rarer. Quite interestingly though a much higher percentage thinks that positive screening methods earn positive excess returns compared to negative screening methods. When we ask respondents to rate different ESG styles and their impact on investment performance we find that negative screening is considered the most detrimental to financial performance. Full integration into stock valuation, active ownership, and positive screening are considered the most beneficial. In general, European investors are more optimistic about the investment value of ESG approaches compared to US investors.

Finally, the sixth set of results relates to how investors will use ESG data in the future. Considering the future, respondents expect that, among different ESG styles, positive screening and active ownership will become more important. Negative screening, thematic investing, best-in-class and full integration in stock valuation are expected to become less important. We find the decline in the importance of full integration in stock valuation the most interesting because at the same time this is 
the style that is identified as the most financially beneficial. Interviews with investment professionals revealed two primary reasons for this finding. The first relates to the challenge we documented before in terms of data quality. Many investors see the lack of comparability and to a lesser extent timeliness and reliability as major impediments of full integration in stock valuation models. The second relates to an industry-wide move towards factor and index investing that favors screening processes compared to bottom-up fundamental analysis.

Our results suggest several directions for future research. First, investors suggest that the financially materiality of different ESG issues varies across sectors consistent with industry-specific accounting standards from the Sustainability Accounting Standards Board (SASB). How the financial materiality of ESG issues could vary also by country or by business model for firms within the same sector is an open question. Second, a large number of investors, especially among US and large investors, suggest that client demand and product development strategies guide their ESG efforts. New innovations in products, such as green bonds or thematic indices, could be laboratories for understanding how markets price preferences for social outcomes. Third, most investors agree that ESG metrics provide useful information on risks but not on competitive positioning. But several companies have developed unique strategies that place environmental and social issues at the core of the company and its brands (e.g. PepsiCo, Unilever, Natura, Novo Nordisk, Discovery, Tesla, Whole Foods). How do these companies communicate their competitive positioning when it comes to environmental or social issues? What are the metrics that provide useful indicators? Moreover, given that comparability of information is a major barrier to further integration in the decision process, we need to better understand sources of comparability and its consequences. For example, have SASB standards or Global Reporting Initiative (GRI) guidelines improved the comparability of reported information? Which industries have higher comparability and why? How differences in comparability over time or across industries have affected how ESG information is reflected in security prices? 
Moreover, investors exhibit different 'ESG styles.' Developing measures of such different styles would be a first step at understanding the consequences of such styles for investment performance. Finally, investors believe that both positive screening and active ownership will become more important styles in the future. How this affects cost of capital and corporate governance practices are important questions for future research.

The remainder of the paper is organized as follows. Section 2 describes the design, dissemination and data collection of the survey instrument. Section 3 reports results on why investors use ESG data in their investment process. Section 4 presents results on how investors use ESG data in the investment process. Section 5 concludes.

\section{Survey Design and Demographic Data}

\section{Survey Design}

We developed a first draft of the survey questions based on a review of the literature on corporate social responsibility and responsible investing (Amel-Zadeh 2016). An internet-based survey instrument was then developed with the help of Institutional Investor Research Group, a financial market's survey design and execution specialist with the aim to reduce biases induced by the questionnaire and to optimize wording and tone of the questions. We solicited feedback on the first draft of the survey from a group of six academic researchers in finance and accounting as well as a group of institutional investors and financial market organizations. ${ }^{3}$ We dropped, shortened, and redrafted survey questions based on feedback received and beta-tested the penultimate version with a small number of investors and financial market experts. The final version of the survey included 30 questions spread over five webpages.

\footnotetext{
3 Among the organizations we received feedback from BNY Mellon's Investor Relations Advisory Group, CFA Institute, IASB, ICAEW, PRI, SEC Professional Reporting Group and several global asset managing and asset owning institutions.
} 
The survey did not require subjects to disclose their names or affiliations, but did allow for space if they chose to do so. Respondents could skip questions if they chose not to answer them other than the basic demographic questions. The order of choices within questions was randomized. The multiple-choice questions allowed for free-text responses or for an exclusive negation of all response choices. Where appropriate we refer to some of the qualitative responses to provide further information.

We distributed the survey via email to a list of senior investment professionals at 4,523 asset managing and asset owning institutions compiled by Bank of New York Mellon and IPREO. The majority of these investment professionals had the title of CEO, CIO, Fund Manager, Portfolio Manager or Investment Analyst. We emailed an invitation to take the survey on 18 January 2016 and closed the survey on 8 April 2016. We received 652 responses, for a response rate of 14.4\%. However, across the survey questions included in the analysis for this study the average response rate is approximately $9 \%$ as some respondents skipped questions or did not fully complete the survey. The response rate is comparable to and somewhat higher than other email-distributed academic surveys in finance and accounting (Graham and Harvey 2001, Graham et al. 2005, Dichev et al. 2013).

\section{Demographic Data}

The survey begins by collecting demographic information about the responding person and institution. We ask for the title/position of the responding person, the type of organization (asset manager, pension fund, insurance firm, endowment, etc.), the location of the firm's headquarters, assets under management, percentage of assets under management allocated to ESG investments, investment focus (diversified, geographically or sector focus), strategy (active versus passive), and asset classes covered. In the subsequent analyses, we report only the conditional results based on AUM, ESG allocation, and geography. 
Table 1 reports the demographic profiles of the responding institutions. The survey captures a large distribution of investors in terms of AUM. 35\% of respondents report AUM below US $\$ 1$ billion while $15 \%$ report AUM of more than US $\$ 100$ billion. Overall, the respondents' total AUM is approximately US $\$ 31$ trillion, which means that the survey captures the opinions of institutional investors with about $43 \%$ of total global assets under management as of year-end $2015 .{ }^{4}$ Moreover, our respondents can generally be considered mainstream investors with almost $70 \%$ reporting less than $10 \%$ of their AUM allocated to ESG investments and half of those reporting no ESG allocation at all. We also do not have any investors among the respondents that are fully specialized on ESG investing, since none of the respondents report 100\% in ESG allocation.

Similarly, among the individuals responding to the survey only $8 \%$ are specialists on ESG investing having the title of ESG investment professional. About quarter of respondents are senior executives (CEO, CIO, CFO or similar) and another quarter are senior fund or portfolio managers (28\%). The majority of investors come from Europe (40\%), followed by North America (34\%) and Asia $(15 \%)$. Almost two thirds of the respondents work for professional asset managers, while the other third works for asset owners such as public and private pension funds (19\%), financial institutions (4\%), charities and endowments (4\%), sovereign wealth funds $(3 \%)$ and family offices $(3 \%)$. Overall, therefore, our sample is likely to reflect the views of a diverse group of largely mainstream investors.

In the subsequent analyses, we condition the results based on whether investors are above the median of US $\$ 5$ billion in AUM (large versus small); based on their ESG allocation at the median cut-off point of 5\% of AUM (high versus low); and based on their geography (US versus Europe).

\footnotetext{
${ }^{4}$ To estimate the respondents' AUM, for those that have identified themselves in the survey we are able to retrieve the respondents' actual AUM figure from secondary sources and otherwise take the mid-point of the AUM range they selected in the survey. Total global AUM comes from a Boston Consulting Group report on the asset management industry available at https://www.bcgperspectives.com/content/articles/financial-institutions-global-asset-management-2016doubling-down-on-data/?chapter=2 (accessed on 17/02/2017).
} 
The size cut-off gives us a value-weighted rather than an equal-weighted view of investor beliefs. The ESG allocation and geography sub-analyses gives us a view on the level of maturity in ESG awareness. We expect that investors with more allocation in ESG and investors in Europe are more ESG-aware.

\section{Why investors use ESG data in their investment process}

\section{What motivates investors to use ESG data?}

Social norms shape economic behavior and may influence market outcomes (Becker 1971; Merton 1987). Social and environmental responsibility has become a societal focal point over the recent years and this trend has spilled over to financial markets. A growing number of socially responsible investors considers ESG information in their investment allocations suggesting that such information has become more important in the investment process. ${ }^{5}$ However, it is still unclear whether mainstream investors, too, use ESG information, and whether they do so having financial motives (i.e., investment performance or increasing client demand) or norms-based (i.e., ethical) motives. Consequently, the first part of the survey asks whether investors consider ESG information when making investment decisions and why.

Table 2 contains the results separated into investors that responded "yes" and "no" to the question whether they consider ESG information in their investment decisions, and their corresponding reasons why. The respondents could first pick "yes" or "no" (which were mutually exclusive) and then the corresponding reasons. Among the reasons the respondents could choose one or more alternatives. In Table 2 the responses are rank ordered by the percentage of respondents that

\footnotetext{
${ }^{5}$ See most recent US SIF (2016) and Eurosif (2016) reports for the growth and size of the responsible investment industry in the United States and Europe. Available at http://www.ussif.org/store_product.asp?prodid=34 (accessed on 19 Feb 2017) and https://www.eurosif.org/sri-study-2016/ (accessed on 19 Feb 2017).
} 
chose each reason. ${ }^{6}$ Respondents also had the option to provide free-text answers for other reasons not provided in the answer list.

The results in Table 2 reveal that a large majority of investors (82\%) consider ESG information when making investment decisions. The percentage is not statistically different between large (above the median AUM of US \$5 billion) and small investors, but increases to $93 \%$ for investors in the high group in terms of ESG allocation (above the median of $5 \%$ of AUM), compared to $75 \%$ for investors with an ESG allocation below the median. This difference is statistically significant (pvalue $<0.01)$. Significant differences also exist between US compared to European investors. A significantly smaller percentage of US investors (75\%) compared to those from Europe $(84 \%)$ responded that they consider ESG information in investment decisions ( $\mathrm{p}$-value $<0.1$ ).

A key finding in Table 2 is that of the investors that do consider ESG information in their investment decisions the majority $(63 \%)$ responded that they do so, because ESG information is financially material to investment performance. This percentage is also statistically significantly different from all other possible response choices. Perhaps not surprisingly, the percentage is higher for investors with a high ESG allocation $(69 \%$ versus $58 \%$, p-value $<0.01)$ and more interestingly is somewhat lower for US compared to European investors (56\% versus 64\%), although the difference is not statistically significant.

There is a distinct cluster of other response choices, all receiving about a third of responses, why investors use ESG information. Among these are in ranking order (i) growing demand from clients and stakeholders; (ii) its effectiveness in changing firms' behavior; (iii) because they consider it part of their product strategy; and (iv) because they see it as their ethical responsibility. Among these a significantly higher percentage of large compared to small firms suggest strategic-financial reasons

\footnotetext{
${ }^{6}$ In the actual Internet survey the response choices were scrambled randomly. That is, different respondents saw different ordering of alternatives.
} 
such as growing client demand $(54 \%$ versus $22 \%$, p-value $<0.01)$ or the development of investment products $(43 \%$ versus $27 \%$, p-value $<0.01)$ among the motivations. The product development motive is also significantly more important for US investors compared to Europeans ( $47 \%$ compared to $30 \%$, p-values<0.01). In contrast, smaller investors are more likely to see the consideration of ESG information in investment decisions as an ethical responsibility ( $36 \%$ compared to $25 \%$, p-value $<0.05$ ) as do European investors compared to US investors (41\% compared to $19 \%$, p-value $<0.01)$. A significantly higher percentage of European compared to US investors also believes ESG considerations to be effective in changing firms' behavior (41\% versus $26 \%$, p-value $<0.05)$.

Among the minority that responded they do not consider ESG information in investment decisions a significantly larger percentage of US investors compared to Europeans think that the information is not material for investment purposes $(22 \%$ versus $4 \%$, p-value $<0.05)$ and that using the information would violate their fiduciary duty $(22 \%$ vs $8 \%)$. The latter finding is interesting in the context of guidance by the US Department of Labor issued in December 2015 that clarifies that using ESG information in investment decisions is not inconsistent with fiduciary duties. Specifically, the DoL guidance states that "[...] environmental, social and governance factors may have a direct relationship to the economic and financial value of an investment'?

Overall, the evidence in our sample suggests that the use of ESG information is driven primarily by financial rather than ethical motives, but that there is considerable variation across geographies. Ethical motives seem to play a larger role in Europe compared to the US and, consistent with this, the former believe more strongly that engagement with companies can bring change in the corporate sector and address ESG issues. The textual responses given under "other" in Table 2 provide some more qualitative statements supporting the quantitative evidence. For example,

\footnotetext{
${ }^{7}$ See U.S. Department of Labor News Release No. 15-2045-NAT. Available at https://www.dol.gov/opa/media/press/ebsa/ebsa20152045.htm (accessed 17 February 2017)
} 
respondents stated that "ESG information is important to assessing investment risk", or "it helps us identify the risks and opportunities of the investments we make for our clients" and further "[ESG information] often can give insight into the "Why" for some of the financial information", all statements that support the financial motive. Among those that do not consider ESG information the majority of "other reasons" relate to the fact that the respondents follow a passive investment strategy, that they "need to be able to quantify non-financial information for a large cross section of stocks" and that it requires "researching which ESG factors are relevant by asset class and industry." We next investigate the underlying financial motive in more detail.

\section{Why is ESG information material for investment decisions?}

A large and diverse literature in economics and management develops several arguments why ESG information might be material for investment value. The literature is too extensive to discuss in detail, but broadly suggests that ESG data provide material information about a company's reputation and brand (Ariely et al. 2009), competitive position (Milgrom and Roberts 1986; Porter and van der Linde 1995), relationship with stakeholders (e.g., regulators, employees, consumers) (McWilliams and Siegel 2001), the quality of management (Besley and Ghatak 2005) and its exposure to litigation and regulatory risk (Benabou and Tirole 2010). ${ }^{8}$ Accordingly, we examine which of these reasons, if any, investors consider the most important in their decision to consider ESG information for investment decision making.

Table 3 presents results on the level of investors' agreement with the reasons why ESG information is material for investment decisions. The table is rank ordered by the average rating (on a scale of 1-4). Table 3 reveals that most respondents believe ESG information to be financially material because it affects a company's reputation and brand. Nearly $97 \%$ of investors agree or strongly agree with the reputational role of ESG data on financial value. Indeed, the average rating for this rationale

\footnotetext{
${ }^{8}$ For a more detailed discussion and review of the literature on the materiality of ESG information see Amel-Zadeh (2016).
} 
is statistically higher than for any of the other seven potential reasons ( $\mathrm{p}$-value $<0.01)$. A close second reason for the suggested materiality of ESG information is that it informs investors about potential litigation and regulatory risk. About $93 \%$ of investors agree or agree strongly with this notion. The average rating for this rational is also statistically greater than for all lower ranked rationales ( $\mathrm{p}$ value $<0.01)$. In contrast to these two highest ranked rationales, both of which relate to a (reputational and legal) risk perspective of ESG, the third ranked with $85 \%$ of the responses suggests that investors believe ESG information signals a company's long-term approach to value creation. Respondents also think that better ESG performance serves as a proxy of management quality or a company's competitive strength albeit less likely compared to the previous three reasons. As in the prior table the materiality of ESG information is primarily of financial nature and less dependent on formal ethical or social mandates of investors, which is ranked last among the seven choices.

Table 3 further reveals few differences among respondents conditional on size, ESG allocation and geography. In fact, there are no notable differences between US and European investors. Unsurprisingly, investors with a high ESG allocation tend to rate all reasons higher and show significantly lower skepticism towards the financial materiality of ESG in general. Overall, respondents believe that a company's environmental, social and governance information is relevant for assessing its reputational, legal and regulatory risk primarily. We next turn to examine which ESG issues are most relevant in the investment process.

\section{Which ESG Issues are Financially Material?}

Prior literature has examined the financial materiality of several different ESG issues. Prior research has documented the presence or absence of an association between carbon emissions (Konar and Cohen 2001), customer satisfaction (Ittner and Larcker 1998), anticorruption efforts (Healy and Serafeim 2016), employee satisfaction (Edmans 2011), supply chain practices (Golicic and Smith 
2013), or community relations (Henisz, Dorobantu and Nartey 2014) and financial performance. Table 4 seeks to shed light on which ESG issues most investors consider to be financially material.

Table 4 shows that most investors find a firms' anticorruption practices to be financially material. This is consistent with Healy and Serafeim (2016), who find that such disclosures predict both media allegations in the future regarding corruption issues, as well as future sales growth and profitability margin changes in high corruption geographic segments. The second issue that most investors consider financially material within the governance space, is leadership and board of directors, consistent with a long stream of literature that seeks to identify the effect of leadership and board on firm performance (Hillman and Dalziel 2003). The next important categories span environmental issues and product information. Most financially material among these are climate change, energy, fuel and waste management information, in support of a literature that examines carbon emissions and their effect on firm value (Matsumura, Prakash and Vera-Munoz 2013) as well as information on the long-term impact of products and their quality and safety. The former are more important to large investors, while the latter seem more important to smaller investors. Furthermore, customer satisfaction and employee health, safety and wellbeing are the other highest scoring items.

All other issues, on average, score lower in the percentage of investors that think they are financially material. Across all issues, biodiversity impacts, product packaging and community relations are the lowest scoring items. Investors with a high ESG allocation, unsurprisingly, find most ESG issues generally more financially material compared to investors with a low ESG allocation, while European investors particularly find more employee and product related information as financially material compared to US investors.

However, these results might be obscuring important differences across different sectors. For example, managing climate change risk can be strategically important for some firms, while employee health and safety issues are more likely to be strategically important for other firms (Eccles and 
Serafeim 2013). Table 5 provides strong evidence that investors are aligned with such an industryspecific view of materiality that is consistent with the standard setting process of the Sustainability Accounting Standards Board (SASB). Khan, Serafeim and Yoon (2016), use SASB's industry classifications of materiality and show that firms that improve their performance on material ESG issues tend to have better stock market and accounting performance in the future. Table 5 shows that climate change is broadly agreed to be financially material for the energy sector followed by basic materials and utilities and then by transportation and industrials. For the remaining sectors the percentage of investors considering climate change as a financially material issue is considerably lower. We find similar effects for energy and water consumption and for waste management practices. However, we note that consistent with mining firms producing vast amounts of waste and consuming large amounts of water we find basic materials rising to the highest scoring sector for those issues.

Governance policies are by a large margin most relevant for the financial sector followed by professional service firms (Khan, Serafeim and Yoon 2016). Impact of products on customers are most relevant for business-to-consumer (B2C) sectors (Eccles, Ioannou and Serafeim 2014). By a large margin the highest scoring sector is consumer and retail, followed by healthcare, financials, technology, median and telecommunications, and professional services. Impact of business activities on local communities is by a large margin most relevant for basic materials firms (Hillman and Dalziel 2003), followed by utilities. Both sectors tend to have very large local impact from their business operations thereby affecting everyday lives of local communities. Financial, healthcare, professional services, and consumer and retail, all B2C sectors, are the highest scoring sectors for employee related policies. Consumer and retail and industrials are the highest scoring sectors for supply chain policies consistent with those sectors relying on robust supply chain to deliver their products but also with these sectors having supply chains that have been the focus of attention for significant social and environmental issues (e.g. labor or pollution). Consumer and retail as well as basic materials are the 
highest scoring sectors for human rights issues, consistent with firms in these sectors having experienced problems with child labor, forced labor, health and safety practices in suppliers over the years (see the case of the Rana Plaza collapse as an example for retail companies and Gold Barrick in Papua New Guinea as an example for basic materials companies).

Overall, Tables 4 and 5 present evidence on how investors view the investment relevance of different ESG issues. Perhaps the most important message is that this varies systematically across sectors. We next turn to examine what factors prevent investors from using ESG information in their investment process.

\section{Barriers to ESG data integration in the investment decision process?}

We found in Table 2 above that almost 18\% do not use ESG information for investment decision making and a sizable portion of these respondents (about 21\%) cites data problems as one impediment. We examine this in more detail in Table 6.

Table 6 presents results on the relative importance of factors that limit investors' ability to use ESG information in their investment decisions. The table is rank ordered by the percentage of responses for each choice. Respondents could select more than one alternative. Table 6 reveals that the greatest challenge investors face in integrating ESG information in their investment process is the lack of cross-company comparability and the lack of standards governing the reporting of ESG information. $45 \%$ and $43 \%$ of respondents state these as the largest impediments. The respondents give slightly less, but similar, weight to the possibility that ESG information is costly to gather and analyze (41\%), lacks detail $(39 \%)$ and is difficult to quantify $(38 \%)$. The percentage differences between all of these choices are not statistically significant.

The respondents assign statistically lower importance to the possibility that ESG disclosures are too infrequent $(28 \%)$ or potentially lack reliability or require external assurance $(26 \%)$. That is, overall investors seem to be satisfied with the timeliness and reliability of ESG disclosures. Moreover, 
only a minority suggests that the reporting of ESG data is too cluttered to be useful $(17 \%)$ or that their client mandates legally prevent them from incorporating ESG information (1.4\%).

Overall, investors globally seem to agree on the main factors that impede an integration of ESG data in the investment process, although a somewhat higher percentage of US investors seem to be concerned about the reliability of the data (32\%) compared to investors from Europe $(27 \%)$. The reliability and a lack of audit of ESG data also concerns large investors significantly more than small investors $(47 \%$ versus $16 \%$, p-value $<0.01)$, and consistent with this so does the lack of reporting standards $(52 \%$ versus $39 \%$, p-value $<0.01)$.

The qualitative comments confirm that a lack of standardization and quantification are the main obstacles to ESG data integration. For example, some investors state that "reliability and standards are the biggest headwinds" or that ESG disclosures are "still a very qualitative approach", while others also demand "sector specific ESG data and industry-adjusted scoring." To further inform investors' data needs we next examine how investors incorporate ESG information in their investment process.

\section{How investors use ESG data in their investment process}

\section{The use of ESG information in the investment process}

Little is known about how investors use ESG information. Traditionally the literature has concentrated on comparing the performance of self-labeled SRI funds compared to conventional mutual funds. In general, these studies find that performance does not differ between SRI and conventional funds (see for example Bauer et al. 2007). A few studies find underperformance of SRI funds (Hong and Kostovetsky 2012) and that this is concentrated in funds that use more screens in their investment process (Barnett and Salomon 2006). While the literature has concentrated on SRI funds that have traditionally used negative screens in their investment process, we know little about how mainstream 
investment organizations use reported ESG information, the granularity of which allows them to move beyond negative screening based on industry membership or involvement in 'sin' businesses.

Table 7 reports results on how investors integrate material ESG information in their investment process. The methods are separated into the use of ESG data at the individual firm (top part of Table 7) and portfolio level (bottom part of Table 7). The possible choices are rank ordered by the percentage of respondents for each choice within these two categories. Respondents were able to select more than one alternative. The table reveals that at the firm level ESG information is used to engage with firms $(37 \%)$ and also integrated into valuation models $(34 \%)$, while at the portfolio level ESG data is mostly used as a screening tool (39\%) and as additional input to portfolio optimization models $(35 \%)$. The proportions of the four methods are not statistically different from each other. They are, however, statistically greater than those for all other response choices.

The use of ESG information as screening tool is more prominent with large investors (58\% versus 30\%, p-value $<0.01)$ and investors with a high ESG allocation ( $52 \%$ versus $30 \%$, p-value $<0.01)$, while the percentage is similar for investors in the US and Europe. Similarly, large investors and investors with a high ESG allocation are more likely to use ESG information to engage with firms ( $43 \%$ versus $34 \%, \mathrm{p}$-value $<0.1$, and $58 \%$ versus $24 \%$, p-value $<0.01$, respectively). In contrast, however, fewer US investors state that they use ESG information for engagement purposes compared to investors from Europe ( $27 \%$ versus $48 \%$, p-value $<0.01)$.

Other uses of ESG information relate to more specialized investment strategies such as impact investments (26\%) and thematic investment (21\%), which are also more prominent in Europe than in the US (29\% and $28 \%$ compared to $20 \%$ and $16 \%$, respectively, p-values $<0.05)$. Moreover, consistent with the results in Table 3 that ESG data is informative to assess a company's risk, Table 7 reveals that at the firm level such information is also used by some investors to estimate firm-specific and 
systematic risks, the latter being more prominent outside of the US $(26 \%$ compared to $17 \%$, pvalue $<0.1)$.

ESG information plays a lesser role in creating portfolio tilts and smart beta strategies and overall almost $17 \%$ of our sample states that they do not use ESG information in their investment process with the percentage being higher for small firms (19\% versus $11 \%$, p-value $<0.05)$, for firms with low ESG allocation (25\% versus 4\%, p-value $<0.01)$, and for US-based investors compared to those from Europe $(22 \%$ versus $12 \%$, p-value $<0.05)$. The finding that US investors are less likely to use ESG data in their investment process, particularly in any other way than as a screening tool, is consistent with these investors having stronger concerns about data reliability (as found in Table 6) as screening methods have the least extensive data needs.

\section{ESG information and financial performance}

We next examine investors' expectations about the financial performance of the firm-level and portfolio-level investment strategies that integrate ESG information as investigated in Table 7. We first ask investors about the expected firm-level effects, that is, whether companies that perform well on ESG metrics have different financial properties than those that perform poorly on these metrics. We then examine the expected financial characteristics of ESG screening methods that investors according to their responses in Table 7 use predominantly at the portfolio-level.

\section{Firm-level performance}

Table 8 reports results on investors' expectations about the characteristics of stocks of companies that perform well on ESG metrics. The possible choices are rank ordered by the percentage of responses for each choice. Respondents were able to select more than one alternative of opposite pairs that were mutually exclusive. The respondents also had the choice to select the mutually exclusive alternative (7) that ESG metrics do not affect the investment characteristics of stocks. 
Table 8 reveals that investors primarily believe that companies with high ESG performance have lower systematic risk $(46 \%)$. The proportion of respondents choosing this alternative is statistically greater than for all other choices ( $\mathrm{p}$-value $<0.01$ ); in particular, compared to its mutually exclusive opposite that these stocks have higher systematic risk (4.2\%). The second and third highest ranked choices are that companies with high ESG performance attract a positive risk premium (31\%) or are underpriced by the market $(24 \%)$, both of which receive statistically higher percentages than their opposite counterparts ( $\mathrm{p}$-value $<0.01$ ). The proportion of respondents for the latter choice is, however, not statistically different compared to the proportion of respondents $(21 \%)$ that believe that ESG metrics do not affect financial performance attributes of stocks.

The three highest ranked choices receive significantly higher ratings from investors with high ESG allocations with 57\% compared to 39\% believing that these stocks have lower systematic risk (pvalue $<0.01), 37 \%$ compared to $27 \%$ stating that they attract a positive risk premium $(\mathrm{p}$-value $<0.1)$ and 34\% compared to 18\% believing that stocks with high ESG performance are underpriced. There is also a significantly higher proportion of European investors compared to US investors that believe high ESG performance is correlated with lower systematic risk (55\% versus $43 \%$, p-value $<0.1)$ and with a positive risk premium (36\% versus $24 \%$, p-value $<0.01)$. Consistent with this finding a higher proportion of US investors believe that the ESG performance of a company is unrelated to its financial attributes $(29 \%$ versus $15 \%$, p-value $<0.05)$, something a significantly higher proportion of smaller investors $(26 \%$ versus $11 \%$, p-value $<0.01)$ and of investors with low ESG allocation $(29 \%$ versus $10 \%$, p-value $<0.01)$ agree with.

Overall Table 8 reveals that investor believe that at the firm-level high ESG performance predominantly affects risk characteristics of the stocks and relatively represents less a characteristic that is underpriced.

\section{Portfolio-level performance}


Table 9 reports results on how investors expect ESG information to affect investment characteristics of portfolios compared to a market index. Panel A summarizes the results for portfolios constructed using negative screening methods and Panel B summarizes the results for positive screening methods. The possible choices are rank ordered by the percentage of responses for each choice. Respondents were able to select more than one alternative across choices and only one within opposite pairs. The respondents also had the choice to select the mutually exclusive alternative (7) that ESG metrics do not affect the investment properties of portfolios.

Regarding negative screening methods, Table 9 panel A reveals that investors predominantly believe that negative screening on ESG metrics reduces a portfolio's risk $(28 \%)$ and earns positive excess returns $(23 \%)$. While these two choices dominate all other choices ( $p$-value $<0.01)$, the proportions are not significantly different from those that believe that negative ESG screening has no effect on investment properties of portfolios $(28 \%)$. The next highest proportions of respondents believe that negative screening reduces diversification benefits and increases the tracking error $(19 \%$ and $18 \%$, respectively). The belief that negative screening reduces the pool of investable assets and is thus detrimental to diversification is more prominent among US investors compared to European investors $(25 \%$ versus $12 \%$, p-value $<0.05)$. Although, more European than US investors believe negatively screened portfolios earn a positive risk premium $(16 \%$ versus $9 \%$, p-value $<0.1)$, significantly more Europeans than US investors also believe that these portfolios earn a negative risk premium as the cost of protection against downside risk $(11 \%$ versus $3 \%$, p-value $<0.05)$.

Regarding positive screening methods, Table 9 panel B reveals that the most dominant belief among investors is that positive screening will lead to positive excess returns (35\%), with no notable differences between US and Europe. However, again the percentage choosing this alternative is not significantly different from the percentage of investors believing that there is no significant effect of positive screening on portfolio characteristics (30\%). Among investors with a high ESG allocation 
the percentage of those believing that positive screening increases excess returns is significantly higher than among those with a low ESG allocation $(44 \%$ compared to $29 \%$, p-value $<0.01)$, while at the same time a higher proportion of the latter thinks that there are no effects $(35 \%$ compared to $23 \%$, p-value $<0.05)$.

The second favorite alternative is that positively screened portfolios earn a positive risk premium (26\%) closely followed by that these portfolio have lower betas or volatility. Among investors that believe these portfolios to earn higher risk premia there is a significantly higher proportion of European compared to US investors (32\% versus $21 \%$, p-value $<0.05)$. Significantly fewer investors believe that positive screening leads to negative excess returns (5\%), increases in the portfolio's beta (4\%) or earns a negative risk premium (4\%).

Table 9 panel $\mathrm{C}$ reports the differences in proportions and tests between negative and positive screening methods. A significantly higher percentage of investors believes positive screening to earn a positive risk premium or positive excess returns compared to negative screening (difference in proportions at $13 \%$ and $12 \%$, respectively, $\mathrm{p}$-values $<0.01)$. More investors believe negative screening to earn negative excess returns ( $\mathrm{p}$-value $=0.01)$, a negative risk premium $(\mathrm{p}$-value $=0.03)$ and to have higher portfolio betas ( $\mathrm{p}$-value $=0.04)$.

Overall the evidence in Table 9 suggests that investors expect positive screening methods to lead to higher returns (either as excess return or in form of a risk premium) while negative screening methods are expected to reduce risk, but also be somewhat detrimental to diversification benefits and more likely than positive screening to earn negative returns. This is perhaps a somewhat surprising finding given that Table 7 shows that negative screening is the most favored approach to integrate ESG information. We next examine this further by investigating ESG integration strategies more widely beyond screening methods both relative to each other and compared to a passive indexing strategy as well as investors' expectations about the future use of these strategies. 


\section{ESG strategies: Financial performance and future integration}

The literature provides mixed evidence on the financial effects of integrating ESG information in the investment process. The inconclusive evidence is likely due to the variety of different strategies that have emerged over the years how investors use and incorporate ESG data in investment selection and portfolio allocation. For example, while some studies find that portfolios that exclude certain firms based on ethical norms (Hong and Kacperczyk 2009) or are formed based on aggregate ESG measures (Brammer et al 2006) underperform their peers, others find that portfolios positively screened on material ESG issues (Khan et al. 2016) or those that are formed based on individual ESG data points such as employee satisfaction (Edmans 2011) outperform their peers. To shed further light on the investment performance of the different ESG integration strategies we investigate investors' expectations about the financial performance and future importance of these strategies.

Table 10 presents results on investors' expectations about the effects of the most commonly used ESG/SRI strategies on investment returns. Respondents were asked to rate the investment impact of different ESG investment strategies compared to a market benchmark on a scale from 1-5, where 1 equals significantly negative, 3 is neutral, and 5 significantly positive. The table is rank ordered by the average rating for the respective strategy. The table reveals that full ESG integration is considered the most beneficial investment strategy by investors in terms of its impact on investment performance. The rating for this strategy is statistically higher than for any other strategy except for active ownership, which is the second highest ranked ESG strategy. $61 \%$ of investors believe that full ESG integration and 53\% believe direct engagement with companies on ESG issues has a moderately or significantly positive impact on financial returns. In contrast, only $6 \%$ and $7 \%$, respectively, believe these strategies to have a moderately or significantly negative impact on returns. The third most beneficial investment strategy is positive screening for which $60 \%$ of investors believe the financial impact to be moderately or significantly positive and $11 \%$ think the opposite. 
Overall, investors consider all strategies except for negative screening methods to have a positive impact on returns as all of these, except for negative screening methods, have a statistically significantly higher rating than 3. Negative screening is the least financially beneficial ESG investment method, albeit with a neutral impact on returns, according to our sampled investors. Only $39 \%$ believe this screening method to have a moderately or significantly positive impact on returns, while $28 \%$ believe it has at least a moderately negative impact.

Investors with a high ESG allocation and those from Europe are generally more optimistic about the financial impact of the different ESG strategies. Somewhat surprisingly large investors are more skeptical about the financial effects of active ownership although they tend to have larger stakes in firms and thus potentially more influence. European investors are significantly more optimistic about the impact of full integration and active ownership compared to US investors (average rating of 3.8 versus 3.5 , p-value $<0.05$ ), while US investors think positive screening has a more positive effect, albeit the differences are not statistically. Risk factor investing and portfolio tilts are also considered more positive for investment returns by European investors than US investors.

Table 11 presents results on how important the ESG investment strategies will be for investors in their investment process in the next five years. Respondents were asked to rank the importance of the ESG investment strategies on a scale from 1-3, from (1) not important to (2) somewhat important to (3) very important. The table is rank ordered by the average rating for the respective strategy.

Overall investors ranked positive screening methods as the most important in the future although its rating is not statistically higher than the rating for active ownership, the second ranked, negative screening, the third ranked, and full integration, the fourth. All four strategies are considered somewhat important in the next five years. In contrast, thematic investment, relative screening, risk factor and impact investment as well as portfolio tilts are all considered less important in the next five 
years by our sample of investors. Their average ratings are statistically significantly lower than 2 (pvalues ranging from $\mathrm{p}<0.01$ to $\mathrm{p}<0.1)$.

Large investors consider positive screening, full integration and thematic investments are more important compared to small investors; and investors with a high ESG allocation naturally assign a higher importance to all ESG strategies than those with a low ESG allocation. More interestingly, investors in Europe consider all strategies, except for positive screening, relatively more important than US investors, with the difference in opinions being the widest for active ownership and impact investments ( $\mathrm{p}$-values $<0.01)$.

Perhaps most surprising here is the decline in the importance of full integration in stock valuation because at the same time this is the style that is identified as the most financially beneficial in Table 10. We interview investment professionals to gain a better understanding of this finding. The interviews reveal two primary reasons. The first relates to problems in data quality documented in Table 6. Many investors see the lack of comparability and quantifiability as major impediments to a full integration of ESG information into stock valuation models. The second relates to an industrywide move towards factor and index investing that favors screening processes compared to bottomup fundamental analysis.

\section{Discussion}

Using survey data from senior investment professionals of organizations around the world we provide insights into why and how investors use ESG data. Moreover, we document what investors believe will be important ESG styles in the future. In interpreting our data, readers should exercise caution. There is a selection bias in who responds to the survey. Therefore, on average we expect that our sample represents more ESG-aware investors. However, at the same time the investors in our sample do not specialize in ESG and represent organizations collectively holding more than $40 \%$ of assets 
under management by institutional investors around the world. Therefore, we believe that the results in this study provide interesting directions for future research.

First, we document that the vast majority of investors are motivated by financial reasons rather than ethical reasons in using ESG data. The majority of the respondents suggests that ESG information is material to investment performance. However, which information is material likely varies systematically across countries (e.g. a country where water pollution is a more serious issue versus a country where corruption is a more serious issues), industries (e.g. an industry affected dramatically by climate change versus an industry affected by violations of human rights in the supply chain) and even firm strategies (e.g. firms that follow differentiation versus low price). For example, Khan et al. (2016) show that the vast majority of ESG data for any given industry is immaterial to investment performance and that the material information varies across industries within a sample of US stocks. Understanding how the materiality of ESG information varies across countries, industries and firm strategies therefore is of primary importance.

Second, a large number of investors use ESG information because of client demand or as part of their product development process. This raises interesting questions about new products that use ESG information. A good example is green bonds where the proceeds of those bonds are to be allocated for projects that improve environmental outcomes. Understanding the structure and pricing of those contracts could shed light into investor preferences and how such financial instruments improve societal outcomes.

Third, investors believe that ESG metrics provide useful information more on risks and less so on competitive positioning. But several companies have developed unique strategies that place environmental and social issues at the core of the company and its brands (e.g. Pepsico, Unilever, Natura, Novo Nordisk, Discovery, Tesla, WholeFoods). This raises a number of important questions. How these companies communicate their competitive positioning when it comes to environmental or 
social issues? What are the metrics that provide useful indicators? Given that corporate strategies are idiosyncratic, is it possible to construct comparable metrics across companies?

Fourth, given that comparability of information is a major barrier to further integration in the decision process, we need to better understand sources of comparability and its consequences. For example, have SASB standards or GRI guidelines improved the comparability of reported information? What has been the role of mandatory ESG reporting regulations in driving comparability (Ioannou and Serafeim 2015)? Which industries have higher comparability and why? How have changes in comparability over time or differences in comparability across industries affected how ESG information is reflected in security prices?

Fifth, we find investors exhibiting different ESG styles. Developing measures of such different styles would be a first step at understanding the consequences of such styles for investment performance. Which investors use positive screening and which investors negative screening? How does the investment process differ? How do investors integrate ESG data in fundamental analysis and stock valuation? What does active ownership mean in the face of increasing indexing?

Finally, investors expect that ESG styles related to positive screening and active ownership will become more important in the future. This creates interesting opportunities for research both in valuation and corporate governance. How does increasing positive screening affect the cost of capital and market valuation of firms that perform well on material ESG issues? Similarly, how does active ownership change firms' governance, managerial practices and performance on ESG issues as well as their financial performance? 


\section{References}

Amel-Zadeh, 2016. The Materiality of Nonfinancial Information: A Review of Theory and Empirical Evidence on Corporate Social Responsibility and Responsible Investing. Said Business School Working Paper.

Ariely, D., A. Bracha, and S. Meier, 2009. Doing Good or Doing Well? Image Motivation and Monetary Incentives in Behaving Prosocially. American Economic Review 99, 544-555.

Bauer, R., Derwall, J. and Otten, R., 2007. The ethical mutual fund performance debate: New evidence from Canada. Journal of Business Ethics, 70(2), pp.111-124.

Barnett, M.L. and Salomon, R.M., 2006. Beyond dichotomy: The curvilinear relationship between social responsibility and financial performance. Strategic Management Journal, 27(11), pp.11011122.

Becker, G. 1971. The Economics of Discrimination, $2^{\text {nd }}$ edition. Chicago: Chicago University Press.

Benabou, R. and J. Tirole, 2010. Individual and Corporate Social Responsibility. Economica 77, 1-19.

Besley, T., and M. Ghatak. 2005. Competition and incentives with motivated agents. American Economic Review 95, 616-636.

Brammer, S., C. Brooks, and S. Pavelin. 2006. Corporate Social Performance and Stock Returns: UK Evidence from Disaggregate Measures. Financial Management, 97-116.

Cheng, B., I. Ioannou, and G. Serafeim, 2014. Corporate Social Responsibility and Access to Finance. Strategic Management Journal 35, 1-23.

Dhaliwal, D. S., O. Z. Li, A. Tsang, and Y. G. Yang. 2011. Voluntary Disclosure and the Cost of Equity Capital: The Initiation of Corporate Social Responsibility Reporting. The Accounting Review 86, 59-100.

Dhaliwal, D. S., S. Radhakrishnan, A. Tsang, and Y. Yang, G. 2012. Nonfinancial Disclosure and Analyst Forecast Accuracy: International Evidence on Corporate Social Responsibility Disclosure. The Accounting Review 87, 723-759.

Dichev, I.D., Graham, J.R., Harvey, C.R., Rajgopal, S., 2013. Earnings Quality: Evidence from the field. Journal of Accounting and Economics 56, 1-33.

Dimson, E., O. Karakaş, and X. Li. 2015. Active Ownership. Review of Financial Studies 28, 3225-3268.

Eccles, R., and G., Serafeim. 2013. The Performance Frontier: Innovating for a Sustainable Strategy. Harvard Business Review 91, no. 5: 50-60.

Eccles, R., Ioannou I., and Serafeim G. 2014. The Impact of Corporate Sustainability on Organizational Processes and Performance. Management Science 60, no. 11: 2835-2857. 
Edmans, A., 2011. Does the stock market fully value intangibles? Employee satisfaction and equity prices. Journal of Financial Economics 101, 621-640.

Golicic, S.L. and Smith, C.D., 2013. A meta-analysis of environmentally sustainable supply chain management practices and firm performance. Journal of supply chain management, 49(2), pp.78-95.

Graham, J.R., Harvey, C.R., 2001. The theory and practice of corporate finance: evidence from the field. Journal of Financial Economics 60, 187-243.

Graham, J.R., Harvey, C.R., Rajgopal, S., 2005. The economic implications of corporate financial reporting. Journal of Accounting and Economics 40, 3-73.

Grewal, J., Riedl, E. and Serafeim, G., 2017. Market Reaction to Mandatory Nonfinancial Disclosure. Harvard Business School Working Paper.

Grewal, J., Hauptman, C. and Serafeim, G. 2017. Stock price synchronicity and material sustainability information. Harvard Business School Working Paper.

Healy, P.M. and Serafeim, G., 2016. An analysis of firms' self-reported anticorruption efforts. The Accounting Review, 91(2), pp.489-511.

Henisz, W.J., Dorobantu, S. and Nartey, L.J., 2014. Spinning gold: The financial returns to stakeholder engagement. Strategic Management Journal, 35(12), pp.1727-1748.

Hillman, A.J. and Dalziel, T., 2003. Boards of directors and firm performance: Integrating agency and resource dependence perspectives. Academy of Management Review, 28(3), pp.383-396.

Hong, H., and M. Kacperczyk. 2009. The price of sin: The effects of social norms on markets. Journal of Financial Economics 93, 15-36.

Hong, H. and Kostovetsky, L., 2012. Red and blue investing: Values and finance. Journal of Financial Economics, 103(1), pp.1-19.

Ioannou, I. and Serafeim, G. 2015. The Consequences of Mandatory Corporate Sustainability Reporting: Evidence from Four Countries. Harvard Business School Research Working Paper No. 11100.

Ittner, C.D. and Larcker, D.F., 1998. Are nonfinancial measures leading indicators of financial performance? An analysis of customer satisfaction. Journal of accounting research, 36, pp.1-35.

Khan, M., G. Serafeim., and A. Yoon. 2016. Corporate Sustainability: First Evidence on Materiality. The Accounting Review 91, 1697-1724.

Konar, S. and Cohen, M.A., 2001. Does the market value environmental performance?. Review of economics and statistics, 83(2), pp.281-289.

Matsumura, E.M., Prakash, R. and Vera-Muñoz, S.C., 2013. Firm-value effects of carbon emissions and carbon disclosures. The Accounting Review, 89(2), pp.695-724. 
McWilliams, A., and D. Siegel, 2001. Corporate Social Responsibility: A Theory of the Firm Perspective. Academy of Management Review 26, 117-127.

Merton, R. 1987. A Simple Model of Capital Market Equilibrium with Incomplete Information. Journal of Finance 42, 483-510.

Milgrom, P., and J. Roberts, 1986. Price and advertising signals of product quality. Journal of Political Economy 94, 796-821.

Porter, M. E. and C. van der Linde, 1995. Towards a new conception of the environmentcompetitiveness relationship. Journal of Economic Perspectives 9, 97-118.

Porter, M. E. and M.R. Kramer, 2011. Creating Shared Value. Harvard Business Review Jan-Feb, 1-17. 
Table 1: Demographic information of investor sample

\begin{tabular}{|c|c|c|c|}
\hline \multicolumn{2}{|c|}{ Assets under Management (in US $\$$ billion) } & \multicolumn{2}{|l|}{ Respondents Titles/Positions } \\
\hline$<1$ & $35 \%$ & Fund/ Portfolio Manager & $28 \%$ \\
\hline $1-5$ & $20 \%$ & Chief Executive Officer & $13 \%$ \\
\hline $5-10$ & $11 \%$ & Investment Analyst/Strategist & $13 \%$ \\
\hline $10-50$ & $12 \%$ & Executive/Managing Director & $11 \%$ \\
\hline $50-100$ & $6 \%$ & Chief Investment Officer & $8 \%$ \\
\hline \multirow[t]{2}{*}{$>100$} & $15 \%$ & ESG/Responsible Investment Specialist & $8 \%$ \\
\hline & $100 \%$ & $\mathrm{CFO} / \mathrm{COO} /$ Chairman/Other Executive & $5 \%$ \\
\hline Percentage of AUM allocated to ESG & & Other & $13 \%$ \\
\hline $0 \%$ & $35 \%$ & & $100 \%$ \\
\hline $1-5 \%$ & $27 \%$ & Geographical Location & \\
\hline $5-10 \%$ & $7 \%$ & Europe & $40 \%$ \\
\hline $10-25 \%$ & $16 \%$ & North America & $34 \%$ \\
\hline $25-50 \%$ & $5 \%$ & Asia & $15 \%$ \\
\hline $50-99 \%$ & $10 \%$ & South America & $3 \%$ \\
\hline \multirow[t]{14}{*}{$100 \%$} & $0 \%$ & Middle east & $3 \%$ \\
\hline & $100 \%$ & Africa & $2 \%$ \\
\hline & & Central America & $1 \%$ \\
\hline & & & $100 \%$ \\
\hline & & Type of Organization & \\
\hline & & Asset Management Company & $65 \%$ \\
\hline & & Corporate Pension Fund & $13 \%$ \\
\hline & & Public/ Local Authority Pension Fund & $6 \%$ \\
\hline & & Charity/ Endowment/ Religious Organization & $4 \%$ \\
\hline & & Insurance/Financial Institution & $4 \%$ \\
\hline & & Sovereign Wealth Fund/ Government Agency & $3 \%$ \\
\hline & & Family office & $2 \%$ \\
\hline & & Other & $2 \%$ \\
\hline & & & $100 \%$ \\
\hline
\end{tabular}


Table 2: ESG information in investment decisions

Survey responses to the question: Do you consider ESG information when making investment decisions?

\begin{tabular}{|c|c|c|c|c|c|c|c|c|c|c|c|c|}
\hline & & \multicolumn{2}{|c|}{ ALL } & \multicolumn{3}{|c|}{ AUM Size } & \multicolumn{3}{|c|}{ ESG Allocation } & \multicolumn{3}{|c|}{ Region } \\
\hline & & (1) & (2) & (3) & (4) & (5) & (6) & (7) & $(8)$ & (9) & $(10)$ & $(11)$ \\
\hline & $\mathrm{N}=419$ & & $\begin{array}{l}\text { Significant } \\
\text { difference } \\
\text { in } \\
\text { proportion } \\
\text { vs. rows }\end{array}$ & Large & Small & $\begin{array}{c}\text { Diff } \\
\text { (3)- } \\
\text { (4) }\end{array}$ & High & Low & $\begin{array}{l}\text { Diff } \\
(6)- \\
(7)\end{array}$ & US & Europe & $\begin{array}{c}\text { Diff } \\
(9)- \\
(10)\end{array}$ \\
\hline & Yes, because... & $82.1 \%$ & & $85.9 \%$ & $80.3 \%$ & & $93.2 \%$ & $75.0 \%$ & $* * *$ & $75.2 \%$ & $84.4 \%$ & $*$ \\
\hline 1 & ... ESG information is material to investment performance & $63.1 \%$ & $2-8$ & $60.3 \%$ & $64.5 \%$ & & $69.3 \%$ & $58.3 \%$ & ** & $55.7 \%$ & $64.4 \%$ & \\
\hline \multirow{2}{*}{$\begin{array}{l}2 \\
3\end{array}$} & ... of growing client/stakeholder demand & $33.1 \%$ & $1,7-8$ & $54.3 \%$ & $22.4 \%$ & $* * *$ & $35.3 \%$ & $31.8 \%$ & & $33.0 \%$ & $39.3 \%$ & \\
\hline & change at firms & $32.6 \%$ & $1,7-8$ & $31.9 \%$ & $32.9 \%$ & & $46.0 \%$ & $22.4 \%$ & $* * *$ & $25.8 \%$ & $40.7 \%$ & $* *$ \\
\hline 4 & ... it is part of our investment product strategy & $32.6 \%$ & $1,7-8$ & $43.1 \%$ & $27.2 \%$ & $* * *$ & $38.7 \%$ & $28.1 \%$ & $* *$ & $47.4 \%$ & $30.4 \%$ & $* * *$ \\
\hline 5 & $\ldots$ we see it as an ethical responsibility & $32.6 \%$ & $1,7-8$ & $25.0 \%$ & $36.4 \%$ & $* *$ & $41.3 \%$ & $26.0 \%$ & $* * *$ & $18.6 \%$ & $40.7 \%$ & $* * *$ \\
\hline 6 & ... we anticipate it to become material in the near future & $31.7 \%$ & $1,7-8$ & $31.9 \%$ & $31.6 \%$ & & $34.0 \%$ & $30.2 \%$ & & $29.9 \%$ & $37.0 \%$ & \\
\hline \multirow[t]{2}{*}{7} & ... of formal client mandates & $25.0 \%$ & $1-3,5-6,8$ & $37.1 \%$ & $18.9 \%$ & $* * *$ & $33.3 \%$ & $18.8 \%$ & $* * *$ & $23.7 \%$ & $30.4 \%$ & \\
\hline & No, because... & $17.9 \%$ & & $14.1 \%$ & $19.7 \%$ & & $6.8 \%$ & $25.0 \%$ & $* * *$ & $24.8 \%$ & $15.6 \%$ & $*$ \\
\hline 1 & ... there is no stakeholder demand for such policy & $26.7 \%$ & $3-5,6-8$ & $15.8 \%$ & $30.4 \%$ & & $9.1 \%$ & $29.7 \%$ & * & $21.9 \%$ & $24.0 \%$ & \\
\hline \multirow{3}{*}{$\begin{array}{l}2 \\
3 \\
4\end{array}$} & $\ldots$ we lack access to reliable nonfinancial data & $21.3 \%$ & $6-7$ & $21.1 \%$ & $21.4 \%$ & & $9.1 \%$ & $23.4 \%$ & & $18.8 \%$ & $32.0 \%$ & \\
\hline & $\begin{array}{l}\text { performance } \\
\text {... we believe such policy to be ineffective in inducing }\end{array}$ & $13.3 \%$ & 1,7 & $5.3 \%$ & $16.1 \%$ & & $18.2 \%$ & $12.5 \%$ & & $21.9 \%$ & $4.0 \%$ & ** \\
\hline & change at firms & $12.0 \%$ & 1,7 & $15.8 \%$ & $10.7 \%$ & & $18.2 \%$ & $10.9 \%$ & & $12.5 \%$ & $16.0 \%$ & \\
\hline \multirow{3}{*}{$\begin{array}{l}5 \\
6 \\
7\end{array}$} & $\ldots$ it would violate our fiduciary duty to our stakeholders & $12.0 \%$ & 1,7 & $5.3 \%$ & $14.3 \%$ & & $9.1 \%$ & $12.5 \%$ & & $21.9 \%$ & $8.0 \%$ & \\
\hline & investment portfolio & $10.7 \%$ & $1-2$ & $5.3 \%$ & $12.5 \%$ & & $9.1 \%$ & $10.9 \%$ & & $6.3 \%$ & $16.0 \%$ & \\
\hline & $\begin{array}{l}\text {... including such information is detrimental to investment } \\
\text { performance }\end{array}$ & $4.0 \%$ & $1-5,8$ & $5.3 \%$ & $3.6 \%$ & & $0.0 \%$ & $4.7 \%$ & * & $6.3 \%$ & $4.0 \%$ & \\
\hline & p-value of difference (yes vs. no) & $<0.001$ & & $<0.001$ & $<0.001$ & & $<0.001$ & $<0.001$ & & $<0.001$ & $<0.001$ & \\
\hline
\end{tabular}

Column (1) presents the percent of respondents choosing the response in a given row. Column (2) shows the results of a t-test of the null hypothesis that the percentage for a given alternative is equal to the percentage for each of the other alternative responses, where only significant differences at the 5 percent level are reported. For example, for response 1 the recorded " $2-8$ " in the column signifies that the percentage for the response in row 1 is significantly different from the percentages for the responses in rows 2 to 8 . Column (3) and (4) report the percentages for investors with AUM $>\$ 5$ billion (large) and AUM $<\$ 5$ billion (small), respectively. Column (5) 
reports the results of a test of the null hypothesis that the percentages in Columns (3) and (4) are equal to each other. Column (5) and (6) report the percentages for investors with ESG allocation $>5 \%$ of AUM (high) and ESG allocation $<5 \%$ of AUM (low), respectively. Column (7) reports the results of a test of the null hypothesis that the percentages in Columns (5) and (6) are equal to each other. Columns (9) to (11) report the percentages by geographical regions and the respective tests of the null hypothesis that the percentages in the specified columns are equal to each other. ${ }^{* *}, * *, *$ denotes significance at the $1 \%, 5 \%$, and $10 \%-l e v e l$, respectively. 
Table 3: The materiality of ESG information

Survey responses to question: To what extent do you agree with the following statements about the materiality of ESG information in investment decision making? (Scale: 4 = Agree Strongly, $3=$ Agree, $2=$ Disagree, $1=$ Disagree Strongly)

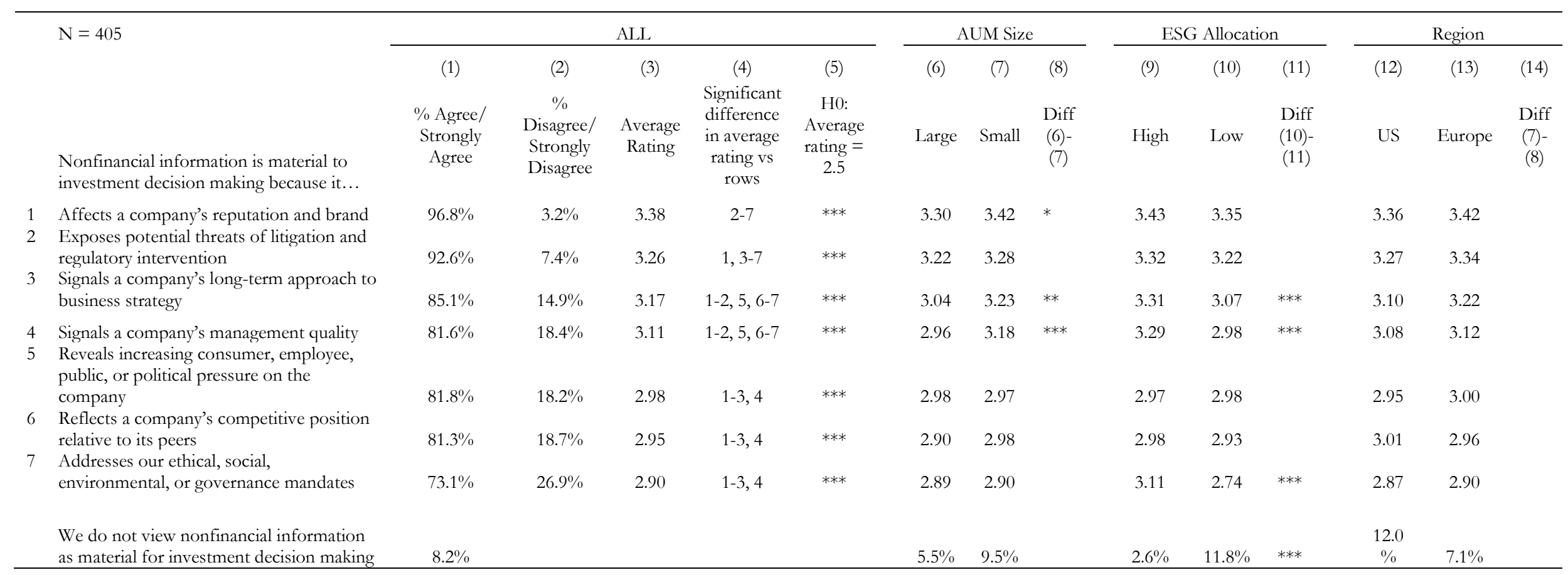

The table reports percentage of respondents and average ratings for all investors. Rows are sorted by average rating in Column (3). Column 1 (2) reports the percentage of respondents indicating agreement levels of 3 or 4 ( 1 or 2$)$ on a scale of 1 to 4 . Column 3 presents the average rating. Column 4 shows the results of a t-test of the null hypothesis that the average rating for a given row is equal to the percentage for each of the other rows, where only significant differences at the 5 percent level are reported. For example, for row 2 the recorded " $1,3-7$ " in the column signifies that the percentage for the response in row 2 is significantly different from the percentages for the responses in rows 1 and 3 to 7 . Column 5 reports the results of a t-test of the null hypothesis that the average rating for a given row is equal to 2.5. Columns (6) and (7) report the average rating for investors with AUM $>\$ 5$ billion (large) and AUM $<\$ 5$ billion (small), respectively. Column (8) reports the results of a t-test of the null hypothesis that the average ratings in Columns (6) and (7) are equal to each other. Column (9) and (10) report the average rating for investors with ESG allocation $>5 \%$ of AUM (high) and ESG allocation $<5 \%$ of AUM (low), respectively. Column (11) reports the results of a t-test of the null hypothesis that the average ratings in Columns (9) and (10) are equal to each other. Columns (12) to (14) report the percentages by geographical regions and the respective tests of the null hypothesis that the percentages in the specified columns are equal to each other. $* * *, * *, *$ denotes significance at the $1 \%, 5 \%$, and $10 \%$-level, respectively. 
Table 4: Material ESG metrics

Survey responses to question: Which ESG information about a company do you consider material to your investment decisions?

\begin{tabular}{|c|c|c|c|c|c|c|c|c|c|c|c|}
\hline \multirow[t]{3}{*}{$\mathrm{N}=357$} & \multicolumn{2}{|c|}{ ALL } & \multicolumn{3}{|c|}{ AUM Size } & \multicolumn{3}{|c|}{ ESG Allocation } & \multicolumn{3}{|c|}{ Region } \\
\hline & (1) & (2) & (3) & (4) & (5) & (6) & (7) & (8) & (9) & $(10)$ & (11) \\
\hline & $\%$ & $\begin{array}{c}\mathrm{z}^{-} \\
\text {score }\end{array}$ & Large & Small & $\begin{array}{c}\text { Diff } \\
(4)-(5)\end{array}$ & High & Low & $\begin{array}{l}\text { Diff } \\
(7)-(8)\end{array}$ & US & Europe & $\begin{array}{c}\text { Diff } \\
(10)-(11)\end{array}$ \\
\hline \multicolumn{12}{|l|}{ ENVIRONMENTAL } \\
\hline Energy and fuel management & $57.7 \%$ & 1.04 & $61.5 \%$ & $55.8 \%$ & & $68.5 \%$ & $50.5 \%$ & $* * *$ & $47.3 \%$ & $63.7 \%$ & $* * *$ \\
\hline Waste and hazardous materials management & $53.5 \%$ & 0.65 & $54.7 \%$ & $52.9 \%$ & & $62.9 \%$ & $47.2 \%$ & $* * *$ & $54.5 \%$ & $59.3 \%$ & \\
\hline Greenhouse gas emissions & $51.9 \%$ & 0.51 & $67.5 \%$ & $44.2 \%$ & $* * *$ & $63.6 \%$ & $43.9 \%$ & $* * *$ & $54.5 \%$ & $61.5 \%$ & \\
\hline Water and wastewater management & $51.3 \%$ & 0.45 & $50.4 \%$ & $51.7 \%$ & & $62.9 \%$ & $43.5 \%$ & $* * *$ & $45.5 \%$ & $55.6 \%$ & \\
\hline Impact of business operations on air quality & $40.6 \%$ & -0.53 & $41.9 \%$ & $40.0 \%$ & & $44.1 \%$ & $38.3 \%$ & & $43.8 \%$ & $43.0 \%$ & \\
\hline Biodiversity impacts & $24.9 \%$ & -1.96 & $24.8 \%$ & $25.0 \%$ & & $33.6 \%$ & $19.2 \%$ & $* * *$ & $16.1 \%$ & $32.6 \%$ & $* * *$ \\
\hline \multicolumn{12}{|l|}{ CUSTOMERS AND THE PUBLIC } \\
\hline Customer/client satisfaction & $52.1 \%$ & 0.53 & $41.9 \%$ & $57.1 \%$ & $* * *$ & $54.5 \%$ & $50.5 \%$ & & $42.0 \%$ & $57.0 \%$ & $* *$ \\
\hline Community relations & $51.8 \%$ & 0.50 & $60.7 \%$ & $47.5 \%$ & $* *$ & $58.0 \%$ & $47.7 \%$ & $*$ & $58.0 \%$ & $51.9 \%$ & \\
\hline Fair disclosure and labeling & $44.8 \%$ & -0.14 & $46.2 \%$ & $44.2 \%$ & & $60.1 \%$ & $34.6 \%$ & $* * *$ & $38.4 \%$ & $53.3 \%$ & $* *$ \\
\hline Human rights & $36.4 \%$ & -0.91 & $32.5 \%$ & $38.3 \%$ & & $46.2 \%$ & $29.9 \%$ & $* * *$ & $30.4 \%$ & $37.0 \%$ & \\
\hline Fair marketing and advertising & $34.7 \%$ & -1.06 & $30.8 \%$ & $36.7 \%$ & & $46.2 \%$ & $27.1 \%$ & $* * *$ & $32.1 \%$ & $35.6 \%$ & \\
\hline Data security and customer privacy & $29.4 \%$ & -1.55 & $23.1 \%$ & $32.5 \%$ & $*$ & $39.2 \%$ & $22.9 \%$ & $* * *$ & $25.0 \%$ & $34.1 \%$ & \\
\hline \multicolumn{12}{|l|}{ HUMAN RESOURCES } \\
\hline Employee health, safety, and well-being & $52.4 \%$ & 0.55 & $49.6 \%$ & $53.8 \%$ & & $65.7 \%$ & $43.5 \%$ & $* * *$ & $40.2 \%$ & $60.7 \%$ & $* * *$ \\
\hline Labor relations & $47.6 \%$ & 0.12 & $45.3 \%$ & $48.8 \%$ & & $58.7 \%$ & $40.2 \%$ & $* * *$ & $40.2 \%$ & $54.8 \%$ & $* *$ \\
\hline Compensation and benefits & $47.3 \%$ & 0.09 & $41.9 \%$ & $50.0 \%$ & & $52.4 \%$ & $43.9 \%$ & & $42.0 \%$ & $53.3 \%$ & $*$ \\
\hline Fair labor practices & $44.8 \%$ & -0.14 & $41.9 \%$ & $46.3 \%$ & & $55.9 \%$ & $37.4 \%$ & $* * *$ & $37.5 \%$ & $50.4 \%$ & $* *$ \\
\hline Recruitment, development, and retention & $43.7 \%$ & -0.24 & $40.2 \%$ & $45.4 \%$ & & $51.7 \%$ & $38.3 \%$ & $* *$ & $40.2 \%$ & $48.9 \%$ & \\
\hline Diversity and inclusion & $36.4 \%$ & -0.91 & $35.0 \%$ & $37.1 \%$ & & $49.0 \%$ & $28.0 \%$ & $* * *$ & $37.5 \%$ & $37.8 \%$ & \\
\hline \multicolumn{12}{|l|}{ PRODUCTS AND SERVICES } \\
\hline The long-term impact & $54.9 \%$ & 0.78 & $54.7 \%$ & $55.0 \%$ & & $61.5 \%$ & $50.5 \%$ & $* *$ & $49.1 \%$ & $63.0 \%$ & $* *$ \\
\hline Product quality and safety & $54.3 \%$ & 0.73 & $45.3 \%$ & $58.8 \%$ & $* *$ & $60.8 \%$ & $50.0 \%$ & $* *$ & $47.3 \%$ & $58.5 \%$ & $*$ \\
\hline Supply chain management & $47.3 \%$ & 0.09 & $47.9 \%$ & $47.1 \%$ & & $55.2 \%$ & $42.1 \%$ & $* *$ & $42.9 \%$ & $54.8 \%$ & $*$ \\
\hline Materials sourcing & $41.2 \%$ & -0.47 & $38.5 \%$ & $42.5 \%$ & & $50.3 \%$ & $35.0 \%$ & $* * *$ & $35.7 \%$ & $46.7 \%$ & $*$ \\
\hline
\end{tabular}




\begin{tabular}{|c|c|c|c|c|c|c|c|c|c|}
\hline Product packaging & $21.3 \%$ & -2.30 & $17.9 \%$ & $22.9 \%$ & $30.1 \%$ & $15.4 \%$ & $* * *$ & $24.1 \%$ & $22.2 \%$ \\
\hline \multicolumn{10}{|l|}{ CORPORATE GOVERNANCE } \\
\hline Codes of conduct, ethics, and anti-corruption & $66.9 \%$ & 1.89 & $64.1 \%$ & $68.3 \%$ & $76.2 \%$ & $60.7 \%$ & $* * *$ & $64.3 \%$ & $68.9 \%$ \\
\hline Leadership and board policies & $66.4 \%$ & 1.83 & $70.1 \%$ & $64.6 \%$ & $73.4 \%$ & $61.7 \%$ & $* *$ & $67.0 \%$ & $68.9 \%$ \\
\hline Stakeholder engagement & $51.0 \%$ & 0.42 & $46.2 \%$ & $53.3 \%$ & $52.4 \%$ & $50.0 \%$ & & $46.4 \%$ & $54.1 \%$ \\
\hline Political influence and transparency & $46.8 \%$ & 0.04 & $41.9 \%$ & $49.2 \%$ & $57.3 \%$ & $39.7 \%$ & $* * *$ & $46.4 \%$ & $53.3 \%$ \\
\hline
\end{tabular}

Colum (1) reports the percentage of respondents choosing the ESG metrics in a given row. Column (2) shows the standardized z-score calculated based on the mean and standard deviation over all metrics. Z-scores in red highlight scores that are more than 0.5 standard deviation above the mean. The ESG metrics follow SASB and GRI definitions. Column (3) and (4) report the percentages for investors with AUM $>\$ 5$ billion (large) and AUM $<\$ 5$ billion (small), respectively. Column (5) reports the results of a test of the null hypothesis that the percentages in Columns (3) and (4) are equal to each other. Column (5) and (6) report the percentages for investors with ESG allocation $>5 \%$ of AUM (high) and ESG allocation $<5 \%$ of AUM (low), respectively. Column (7) reports the results of a test of the null hypothesis that the percentages in Columns (5) and (6) are equal to each other. Columns (9) to (11) report the percentages by geographical regions and the respective tests of the null hypothesis that the percentages in the specified columns are equal to each other. ${ }^{* *}$, $* *$, * denotes significance at the $1 \%, 5 \%$, and $10 \%$-level, respectively. 
Table 5: Sector Materiality

Survey responses to question: Which ESG issues are likely to be material for companies in the various sectors?

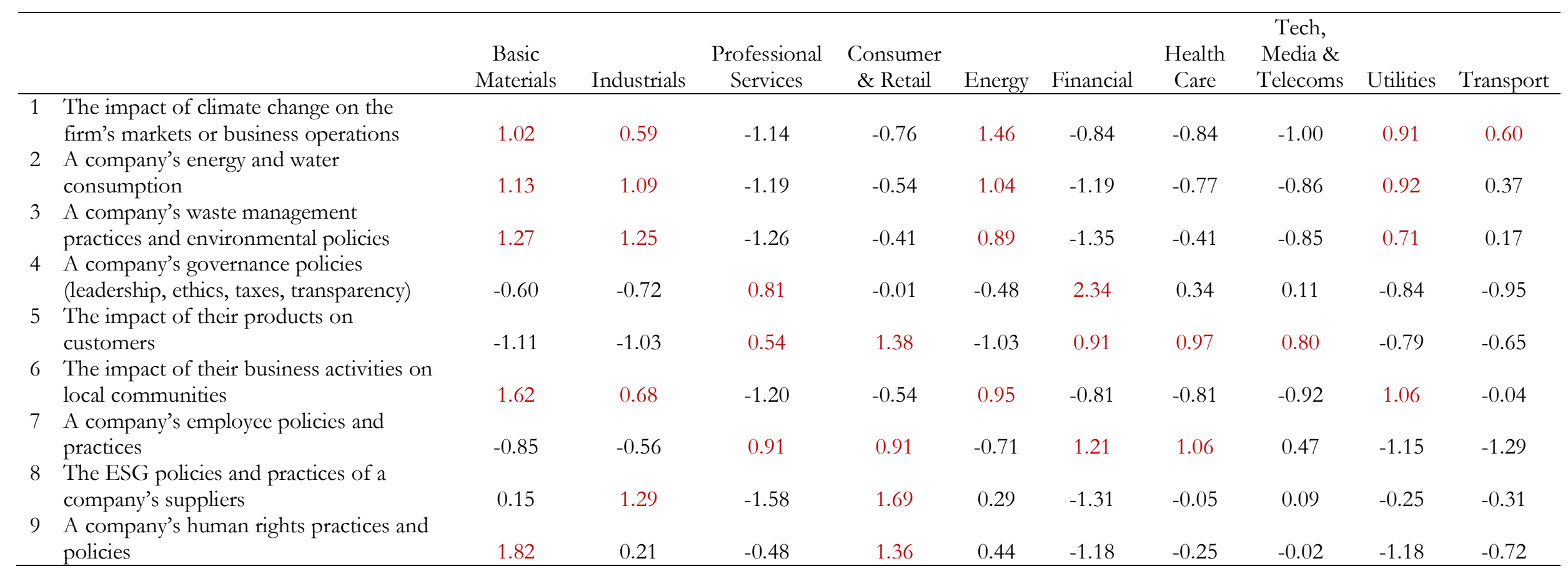

The table reports the standardized z-score calculated based on the mean and standard deviation of percentage of responses by ESG issue in the rows across all sectors. Z-scores in red highlight scores that are more than 0.5 standard deviation above the mean. 
Table 6: Impediments to ESG integration

Survey responses to question: Which of the following factors limit your firm's ability to use ESG information in your investment decisions?

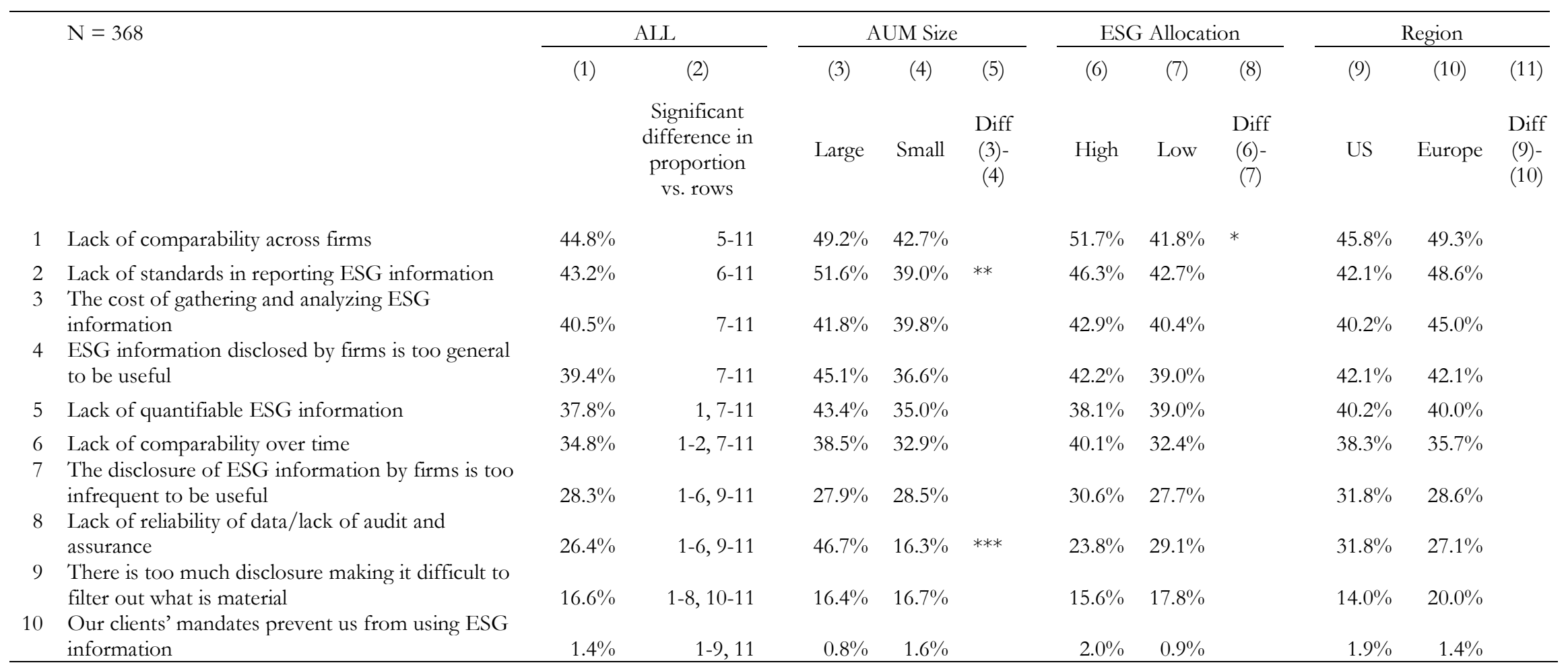

Column (1) presents the percentage of respondents choosing the response in a given row. Column (2) shows the results of a t-test of the null hypothesis that the percentage for a given alternative is equal to the percentage for each of the other alternative responses, where only significant differences at the 5 percent level are reported. For example, for response 1 the recorded " $5-11$ " in the column signifies that the percentage for the response in row 1 is significantly different from the percentages for the responses in rows 5 to 11 . Column (3) and (4) report the percentages for investors with AUM $>\$ 5$ billion (large) and AUM $<\$ 5$ billion (small), respectively. Column (5) reports the results of a test of the null hypothesis that the percentages in Columns (3) and (4) are equal to each other. Column (5) and (6) report the percentages for investors with ESG allocation $>5 \%$ of AUM (high) and ESG allocation $<5 \%$ of AUM (low), respectively. Column (7) reports the results of a test of the null hypothesis that the percentages in Columns (5) and (6) are equal to each other. Columns (9) to (11) report the percentages by geographical regions and the respective tests of the null hypothesis that the percentages in the specified columns are equal to each other. $* * *, * *, *$ denotes significance at the $1 \%, 5 \%$, and $10 \%$-level, respectively. 
Table 7: ESG integration

Survey responses to question: How do you integrate material ESG information in your investment process?

\begin{tabular}{|c|c|c|c|c|c|c|c|c|c|c|c|}
\hline \multirow[t]{3}{*}{$\mathrm{N}=337$} & \multicolumn{2}{|c|}{ ALL } & \multicolumn{3}{|c|}{ AUM Size } & \multicolumn{3}{|c|}{ ESG Allocation } & \multicolumn{3}{|c|}{ Region } \\
\hline & (1) & (2) & (3) & (4) & (5) & (6) & (7) & (8) & (9) & (10) & (11) \\
\hline & & $\begin{array}{l}\text { Significant } \\
\text { difference in } \\
\text { proportion } \\
\text { vs. rows }\end{array}$ & Large & Small & $\begin{array}{c}\text { Diff } \\
(3)- \\
(4)\end{array}$ & High & Low & $\begin{array}{l}\text { Diff } \\
(6)- \\
(7)\end{array}$ & US & Europe & $\begin{array}{l}\text { Diff } \\
(9)- \\
(10)\end{array}$ \\
\hline & & & & & At th & level & & & & & \\
\hline
\end{tabular}

To engage with the firms we invest in

As additional input integrated into our valuation model of individual stocks

3 As part of our impact investing engagements

4 As additional input to estimate a stock's idiosyncratic risk

5 As additional input to estimate a stock's systematic risk

$\begin{array}{rrrrrrrrrrr}37.1 \% & 3-5,8-11 & 42.7 \% & 34.4 \% & * & 57.6 \% & 23.9 \% & * * * & 27.1 \% & 48.1 \% & * * * \\ 34.4 \% & 3-5,8-11 & 37.3 \% & 33.0 \% & & 43.2 \% & 28.8 \% & * * * & 27.1 \% & 35.9 \% & \\ 26.4 \% & 1-2,6-11 & 28.2 \% & 25.6 \% & & 38.6 \% & 18.5 \% & * * * & 19.6 \% & 29.0 \% & * \\ 23.4 \% & 1-2,6-7,9-11 & 29.1 \% & 20.7 \% & * & 28.0 \% & 20.5 \% & & 18.7 \% & 26.0 \% & \\ 23.1 \% & 1-2,6-7,9-11 & 18.2 \% & 25.6 \% & & 32.6 \% & 17.1 \% & * * * & 16.8 \% & 26.0 \% & *\end{array}$

At the portfolio level

6 As a screening tool to define the investment universe

7 As additional input to estimates of expected returns and variances

8 To create thematic investment portfolios (e.g., green energy, sustainable agriculture)

9 As an overlay to tilt our portfolio or index investments toward high ESG performance

10 As additional risk premium in alternative/smart beta strategies

\begin{tabular}{|c|c|c|c|c|c|c|c|c|c|}
\hline $38.9 \%$ & $3-5,8-11$ & $58.2 \%$ & $29.5 \%$ & $* * *$ & $52.3 \%$ & $30.2 \%$ & $* * *$ & $45.8 \%$ & $45.0 \%$ \\
\hline $35.0 \%$ & $3-5,8-11$ & $33.6 \%$ & $35.7 \%$ & & $39.4 \%$ & $32.2 \%$ & & $34.6 \%$ & $32.1 \%$ \\
\hline $20.8 \%$ & $1-3,6-7,9-11$ & $29.1 \%$ & $16.7 \%$ & $* *$ & $26.5 \%$ & $17.1 \%$ & $* *$ & $15.9 \%$ & $26.7 \%$ \\
\hline $14.2 \%$ & $1-8$ & $20.0 \%$ & $11.5 \%$ & $* *$ & $20.5 \%$ & $10.2 \%$ & $* *$ & $13.1 \%$ & $19.1 \%$ \\
\hline $11.3 \%$ & $1-8,11$ & $9.1 \%$ & $12.3 \%$ & & $15.2 \%$ & $8.8 \%$ & * & $6.5 \%$ & $11.5 \%$ \\
\hline
\end{tabular}

11 We do not use ESG information in our investment process 
Column (1) presents the percentage of respondents choosing the response in a given row. Column (2) shows the results of a t-test of the null hypothesis that the percentage for a given alternative is equal to the percentage for each of the other alternative responses, where only sionificant differences at the 5 percent level are reported. For example, for response 1 the recorded " $3-5,8-11$ " in the column signifies that the percentage for the response in row 1 is significantly different from the percentages for the responses in rows 3 to 5 and 8 to 11 . Column (3) and (4) report the percentages for investors with AUM $>\$ 5$ billion (large) and AUM $<\$ 5$ billion (small), respectively. Column (5) reports the results of a test of the null hypothesis that the percentages in Columns (3) and (4) are equal to each other. Column (5) and (6) report the percentages for investors with ESG allocation $>5 \%$ of AUM (high) and ESG allocation < 5\% of AUM (low), respectively. Column (7) reports the results of a test of the null hypothesis that the percentages in Columns (5) and (6) are equal to each other. Columns (9) to (11) report the percentages by geographical regions and the respective tests of the null hypothesis that the percentages in the specified columns are equal to each other. ***, **, * denotes significance at the $1 \%, 5 \%$, and $10 \%$-level, respectively. 
Table 8: The effects of ESG on investment characteristics of stocks

Survey responses to question: How do you expect ESG information to affect investment characteristics of stocks?

\begin{tabular}{|c|c|c|c|c|c|c|c|c|c|c|c|c|}
\hline & \multirow[b]{2}{*}{$\mathrm{N}=313$} & \multicolumn{2}{|r|}{ ALL } & \multicolumn{3}{|c|}{ AUM Size } & \multicolumn{3}{|c|}{ ESG Allocation } & \multicolumn{3}{|c|}{ Region } \\
\hline & & (1) & (2) & (3) & (4) & (5) & (6) & (7) & (8) & (9) & $(10)$ & (11) \\
\hline & $\begin{array}{l}\text { Companies with bigh performance on ESG } \\
\text { metrics... }\end{array}$ & & $\begin{array}{l}\text { Significant } \\
\text { difference in } \\
\text { proportion } \\
\text { vs. rows }\end{array}$ & Large & Small & $\begin{array}{l}\text { Diff } \\
(3)- \\
(4)\end{array}$ & High & Low & $\begin{array}{l}\text { Diff } \\
(6)- \\
(7)\end{array}$ & US & Europe & $\begin{array}{l}\text { Diff } \\
(9)- \\
(10)\end{array}$ \\
\hline 1 & $\begin{array}{l}\text {...have lower systematic risk and thus } \\
\text { a lower market beta }\end{array}$ & $46.3 \%$ & $2-7$ & $51.5 \%$ & $43.8 \%$ & & $57.4 \%$ & $39.3 \%$ & $* * *$ & $42.6 \%$ & $55.1 \%$ & $*$ \\
\hline 3 & $\begin{array}{l}\text {...attract a positive risk premium not } \\
\text { captured by their market beta } \\
\text {...are underpriced by the market and } \\
\text { thus experience higher investment }\end{array}$ & $31.0 \%$ & $1,3-7$ & $35.9 \%$ & $28.6 \%$ & & $36.9 \%$ & $27.2 \%$ & * & $23.8 \%$ & $36.4 \%$ & $* *$ \\
\hline & alpha & $24.3 \%$ & $1-2,4-6$ & $27.2 \%$ & $22.9 \%$ & & $34.4 \%$ & $17.8 \%$ & $* * *$ & $24.8 \%$ & $25.4 \%$ & \\
\hline 4 & $\begin{array}{l}\text {...attract a negative risk premium and } \\
\text { thus have insurance-like properties } \\
\ldots \text { are overpriced by the market and } \\
\text { thus experience lower investment }\end{array}$ & $10.5 \%$ & $1-3,6-7$ & $8.7 \%$ & $11.4 \%$ & & $11.5 \%$ & $9.9 \%$ & & $10.9 \%$ & $14.4 \%$ & \\
\hline & $\begin{array}{l}\text { alpha } \\
\text {...have higher svstematic risk and thus }\end{array}$ & $9.3 \%$ & $1-3,6-7$ & $9.7 \%$ & $9.0 \%$ & & $9.0 \%$ & $9.4 \%$ & & $11.9 \%$ & $7.6 \%$ & \\
\hline & a higher market beta & $4.2 \%$ & $1-5,7$ & $5.8 \%$ & $3.3 \%$ & & $3.3 \%$ & $4.7 \%$ & & $5.9 \%$ & $3.4 \%$ & \\
\hline 7 & $\begin{array}{l}\text { ESG information does not affect } \\
\text { investment properties of stocks }\end{array}$ & $21.4 \%$ & $1-2,4-6$ & $11.4 \%$ & $25.7 \%$ & $* * *$ & $9.8 \%$ & $28.8 \%$ & $* * *$ & $28.7 \%$ & $15.3 \%$ & $* *$ \\
\hline
\end{tabular}

Column (1) presents the percentage of respondents choosing the response in a given row. Column (2) shows the results of a t-test of the null hypothesis that the percentage for a given alternative is equal to the percentage for each of the other alternative responses, where only significant differences at the 5 percent level are reported. For example, for response 1 the recorded " $2-7$ " in the column signifies that the percentage for the response in row 1 is significantly different from the percentages for the responses in rows 2 to 7 . Column (3) and (4) report the percentages for investors with AUM $>\$ 5$ billion (large) and AUM $<\$ 5$ billion (small), respectively. Column (5) reports the results of a test of the null hypothesis that the percentages in Columns (3) and (4) are equal to each other. Column (5) and (6) report the percentages for investors with ESG allocation $>5 \%$ of AUM (high) and ESG allocation $<5 \%$ of AUM (low), respectively. Column (7) reports the results of a test of the null hypothesis that the percentages in Columns (5) and (6) are equal to each other. Columns (9) to (11) report the percentages by geographical regions and the respective tests of the null hypothesis that the percentages in the specified columns are equal to each other. $* * *, * *, *$ denotes significance at the $1 \%, 5 \%$, and $10 \%$-level, respectively. 
Table 9: The effects of ESG on investment characteristics of portfolios

Survey responses to question: How do you expect ESG information to affect investment characteristics of a portfolio compared to a market index benchmark?

\begin{tabular}{|c|c|c|c|c|c|c|c|c|c|c|c|c|}
\hline & \multicolumn{12}{|c|}{ Panel A: Investment strategies that involve negative ESG screening methods } \\
\hline & \multirow[t]{2}{*}{$\mathrm{N}=320$} & \multicolumn{2}{|c|}{ ALL } & \multicolumn{3}{|c|}{ AUM Size } & \multicolumn{3}{|c|}{ ESG Allocation } & \multicolumn{3}{|c|}{ Region } \\
\hline & & $(1)$ & $(2)$ & (3) & (4) & (5) & (6) & (7) & (8) & (9) & (10) & (11) \\
\hline & & & $\begin{array}{l}\text { Significant } \\
\text { difference in } \\
\text { proportion } \\
\text { vs. rows }\end{array}$ & Large & Small & $\begin{array}{l}\text { Diff } \\
(3)- \\
(4)\end{array}$ & High & Low & $\begin{array}{l}\text { Diff } \\
(6)- \\
(7)\end{array}$ & US & Europe & $\begin{array}{l}\text { Diff } \\
(9)- \\
(10)\end{array}$ \\
\hline 1 & $\begin{array}{l}\text { Reduce a portfolio's market beta and/or } \\
\text { volatility }\end{array}$ & $27.5 \%$ & $3-8$ & $32.1 \%$ & $25.2 \%$ & & $28.2 \%$ & $27.0 \%$ & & $28.4 \%$ & $30.9 \%$ & \\
\hline 2 & Earn positive excess returns (alpha) & $23.1 \%$ & $5-8$ & $25.5 \%$ & $22.0 \%$ & & $25.8 \%$ & $21.4 \%$ & & $20.6 \%$ & $23.6 \%$ & \\
\hline 3 & Reduce diversification benefits & $18.8 \%$ & $1,6-9$ & $18.9 \%$ & $18.7 \%$ & & $19.4 \%$ & $18.4 \%$ & & $24.5 \%$ & $12.2 \%$ & ** \\
\hline 4 & Increase the tracking error & $18.4 \%$ & $1,6-9$ & $18.9 \%$ & $18.2 \%$ & & $21.8 \%$ & $16.3 \%$ & & $19.6 \%$ & $17.1 \%$ & \\
\hline 5 & Load on a positive ESG risk premium & $13.4 \%$ & $1-2,9$ & $15.1 \%$ & $12.6 \%$ & & $20.2 \%$ & $9.2 \%$ & $* * *$ & $8.8 \%$ & $16.3 \%$ & $*$ \\
\hline 6 & Earn negative excess returns (alpha) & $10.6 \%$ & $1-4,9$ & $7.5 \%$ & $12.1 \%$ & & $6.5 \%$ & $13.3 \%$ & $* *$ & $13.7 \%$ & $12.2 \%$ & \\
\hline 7 & Load on a negative ESG risk premium & $8.1 \%$ & $1-4,9$ & $5.7 \%$ & $9.3 \%$ & & $10.5 \%$ & $6.6 \%$ & & $2.9 \%$ & $11.4 \%$ & ** \\
\hline 8 & $\begin{array}{l}\text { Increase a portfolio's market beta and/or } \\
\text { volatility }\end{array}$ & $7.8 \%$ & $1-5,9$ & $6.6 \%$ & $8.4 \%$ & & $8.9 \%$ & $7.1 \%$ & & $8.8 \%$ & $7.3 \%$ & \\
\hline 9 & $\begin{array}{l}\text { Have no significant effect on investment } \\
\text { properties of portfolios }\end{array}$ & $28.1 \%$ & $3-8$ & $25.5 \%$ & $29.4 \%$ & & $21.8 \%$ & $32.1 \%$ & $* *$ & $30.4 \%$ & $26.0 \%$ & \\
\hline
\end{tabular}


Table 9: The effects of ESG on investment characteristics of portfolios (continued)

Panel B: Investment strategies that involve positive ESG screening methods

\begin{tabular}{|c|c|c|c|c|c|c|c|c|c|c|c|c|}
\hline & & \multicolumn{2}{|c|}{ ALL } & \multicolumn{3}{|c|}{ AUM Size } & \multicolumn{3}{|c|}{ ESG Allocation } & \multicolumn{3}{|l|}{ Region } \\
\hline & & (1) & $(2)$ & (3) & (4) & (5) & $(6)$ & (7) & $(8)$ & $(9)$ & (10) & $(11)$ \\
\hline & $\mathrm{N}=320$ & & $\begin{array}{l}\text { Significant } \\
\text { difference in } \\
\text { proportion } \\
\text { vs. rows }\end{array}$ & Large & Small & $\begin{array}{l}\text { Diff } \\
(3)- \\
(4)\end{array}$ & High & Low & $\begin{array}{l}\text { Diff } \\
(6)- \\
(7)\end{array}$ & US & Europe & $\begin{array}{l}\text { Diff } \\
(9)- \\
(10)\end{array}$ \\
\hline 1 & Earn positive excess returns (alpha) & $34.7 \%$ & $3-8$ & $30.2 \%$ & $36.9 \%$ & & $44.4 \%$ & $28.6 \%$ & $* * *$ & $33.3 \%$ & $37.4 \%$ & \\
\hline 2 & Load on a positive ESG risk premium & $26.3 \%$ & $5-8$ & $22.6 \%$ & $28.0 \%$ & & $41.9 \%$ & $16.3 \%$ & $* * *$ & $20.6 \%$ & $31.7 \%$ & $* *$ \\
\hline 3 & Reduce a portfolio's market beta or volatility & $24.1 \%$ & $1,5-8$ & $31.1 \%$ & $20.6 \%$ & $* *$ & $26.6 \%$ & $22.4 \%$ & & $26.5 \%$ & $24.4 \%$ & \\
\hline 4 & Increase the tracking error & $18.8 \%$ & $1-3,6-9$ & $20.8 \%$ & $17.8 \%$ & & $21.8 \%$ & $16.8 \%$ & & $21.6 \%$ & $19.5 \%$ & \\
\hline 5 & Reduce diversification benefits & $14.1 \%$ & $1-3,6-9$ & $12.3 \%$ & $15.0 \%$ & & $16.1 \%$ & $12.8 \%$ & & $16.7 \%$ & $13.0 \%$ & \\
\hline 6 & Earn negative excess returns (alpha) & $5.3 \%$ & $1-5,9$ & $2.8 \%$ & $6.5 \%$ & * & $6.5 \%$ & $4.6 \%$ & & $4.9 \%$ & $5.7 \%$ & \\
\hline 7 & Increase a portfolio's market beta or volatility & $4.1 \%$ & $1-5,9$ & $2.8 \%$ & $4.7 \%$ & & $6.5 \%$ & $2.6 \%$ & & $4.9 \%$ & $2.4 \%$ & \\
\hline 8 & Load on a negative ESG risk premium & $4.1 \%$ & $1-5,9$ & $2.8 \%$ & $4.7 \%$ & & $5.6 \%$ & $3.1 \%$ & & $3.9 \%$ & $6.5 \%$ & \\
\hline \multirow[t]{11}{*}{9} & $\begin{array}{l}\text { Have no significant effect on investment } \\
\text { properties of portfolios }\end{array}$ & $30.0 \%$ & $4-8$ & $29.2 \%$ & $30.4 \%$ & & $22.6 \%$ & $34.7 \%$ & $* *$ & $34.3 \%$ & $26.0 \%$ & \\
\hline & \multicolumn{12}{|c|}{ Panel C: $p$-values for differences between positive and negative ESG screening methods } \\
\hline & & Difference & p-value & & & & & & & & & \\
\hline & Load on a positive ESG risk premium & $-12.8 \%$ & 0.00 & & & & & & & & & \\
\hline & Earn positive excess returns (alpha) & $-11.6 \%$ & 0.00 & & & & & & & & & \\
\hline & Earn negative excess returns (alpha) & $5.3 \%$ & 0.01 & & & & & & & & & \\
\hline & Load on a negative ESG risk premium & $4.1 \%$ & 0.03 & & & & & & & & & \\
\hline & Increase a portfolio's market beta or volatility & $3.8 \%$ & 0.04 & & & & & & & & & \\
\hline & Reduce diversification benefits & $4.7 \%$ & 0.11 & & & & & & & & & \\
\hline & $\begin{array}{l}\text { Reduce a portfolio's market beta or volatility } \\
\text { Have no significant effect on investment } \\
\text { properties of portfolios }\end{array}$ & $\begin{array}{l}3.4 \% \\
-1.9 \%\end{array}$ & 0.32 & & & & & & & & & \\
\hline & Increase the tracking error & $-0.3 \%$ & 0.92 & & & & & & & & & \\
\hline
\end{tabular}


In Panel A and B Column (1) presents the percentage of respondents choosing the response in a given row. Column (2) shows the results of a t-test of the null hypothesis that the percentage for a given alternative is equal to the percentage for each of the other alternative responses, where only significant differences at the 5 percent level are reported. For example, for response 1 the recorded " $3-8$ " in the column signifies that the percentage for the response in row 1 is significantly different from the percentages for the responses in rows 3 to 8 . Column (3) and (4) report the percentages for investors with AUM $>\$ 5$ billion (large) and AUM $<\$ 5$ billion (small), respectively. Column (5) reports the results of a test of the null hypothesis that the percentages in Columns (3) and (4) are equal to each other. Column (5) and (6) report the percentages for investors with ESG allocation $>5 \%$ of AUM (high) and ESG allocation < 5\% of AUM (low), respectively. Column (7) reports the results of a test of the null hypothesis that the percentages in Columns (5) and (6) are equal to each other. Columns (9) to (11) reports the percentages by geographical regions and the respective tests of the null hypothesis that the percentages in the specified columns are equal to each other. $* * *, * *, *$ denotes significance at the $1 \%, 5 \%$, and $10 \%$-level, respectively. In Panel C, Column (1) reports the difference in percentage of respondents for the respective rows between Panel A and Panel B. Column (20 reports the p-values of a t-test test of the null hypothesis that the percentages in Panel A and Panel B are equal to each other. 
Table 10: ESG strategies and investment returns

Survey responses to question: Which of the following ESG strategies do you believe improve or reduce investment returns compared to a market benchmark? (Scale: $5=$ significantly positive, $4=$ moderately positive, $3=$ neutral, $2=$ moderately negative, $1=$ significantly negative)

\begin{tabular}{|c|c|c|c|c|c|c|c|c|c|c|c|c|c|c|c|}
\hline & \multirow[t]{3}{*}{$\mathrm{N}=295$} & \multicolumn{5}{|c|}{ ALL } & \multicolumn{3}{|c|}{ AUM Size } & \multicolumn{3}{|c|}{ ESG Allocation } & \multicolumn{3}{|c|}{ Region } \\
\hline & & (1) & (2) & (3) & (4) & (5) & (6) & (7) & (8) & (9) & $(10)$ & (11) & $(12)$ & (13) & (14) \\
\hline & & $\begin{array}{c}\% \\
\text { moderately/ } \\
\text { significantly } \\
\text { positive }\end{array}$ & $\begin{array}{c}\% \\
\text { moderately/ } \\
\text { significantly } \\
\text { negative }\end{array}$ & $\begin{array}{l}\text { Average } \\
\text { Rating }\end{array}$ & $\begin{array}{l}\text { Significant } \\
\text { difference } \\
\text { in average } \\
\text { rating vs } \\
\text { rows }\end{array}$ & $\begin{array}{c}\mathrm{H} 0: \\
\text { Average } \\
\text { rating = } \\
3\end{array}$ & Large & Small & $\begin{array}{l}\text { Diff } \\
\text { (6)- } \\
(7)\end{array}$ & High & Low & $\begin{array}{l}\text { Diff } \\
(9)- \\
(10)\end{array}$ & US & Europe & $\begin{array}{c}\text { Diff } \\
(12) \\
(13)\end{array}$ \\
\hline 1 & $\begin{array}{l}\text { Full integration into individual } \\
\text { stock valuation }\end{array}$ & $61.2 \%$ & $5.8 \%$ & 3.71 & $3-9$ & $* * *$ & 3.70 & 3.71 & & 3.96 & 3.53 & $* * *$ & 3.54 & 3.81 & ** \\
\hline 2 & Engagement/active ownership & $52.7 \%$ & $6.5 \%$ & 3.63 & $1,5-9$ & $* * *$ & 3.47 & 3.70 & ** & 3.83 & 3.48 & $* * *$ & 3.46 & 3.80 & $* * *$ \\
\hline 3 & Positive screening & $59.6 \%$ & $10.5 \%$ & 3.55 & $1,5-9$ & $* * *$ & 3.64 & 3.51 & & 3.69 & 3.45 & $* *$ & 3.60 & 3.56 & \\
\hline 4 & $\begin{array}{l}\text { Risk factor/ risk premium } \\
\text { investing }\end{array}$ & $42.4 \%$ & $8.4 \%$ & 3.49 & $1,7-9$ & $* * *$ & 3.43 & 3.52 & & 3.70 & 3.35 & $* * *$ & 3.26 & 3.52 & ** \\
\hline 5 & $\begin{array}{l}\text { Relative screening/ best-in-class } \\
\text { screening }\end{array}$ & $49.7 \%$ & $11.0 \%$ & 3.46 & $1,7-9$ & $* * *$ & 3.34 & 3.52 & * & 3.67 & 3.32 & $* * *$ & 3.38 & 3.49 & \\
\hline 6 & Thematic investment & $42.4 \%$ & $10.4 \%$ & 3.37 & $1-3,9$ & $* * *$ & 3.35 & 3.38 & & 3.42 & 3.34 & & 3.34 & 3.36 & \\
\hline 7 & Overlay/portfolio tilt & $37.4 \%$ & $11.0 \%$ & 3.31 & $1-5,9$ & $* * *$ & 3.24 & 3.35 & & 3.49 & 3.18 & $* * *$ & 3.17 & 3.31 & $* *$ \\
\hline 8 & Impact investment & $37.1 \%$ & $12.9 \%$ & 3.25 & $1-5,9$ & $* * *$ & 3.19 & 3.28 & & 3.35 & 3.19 & & 3.14 & 3.28 & \\
\hline 9 & Negative screening & $39.1 \%$ & $28.2 \%$ & 3.09 & $1-8$ & & 3.07 & 3.09 & & 3.14 & 3.05 & & 3.07 & 3.12 & \\
\hline
\end{tabular}

Column 1 (2) reports the percentage of respondents indicating the impact levels of 4 or 5 (1 or 2 ) on a scale of 1 to 5 . Column 3 presents the average rating. Column 4 shows the results of a t-test of the null hypothesis that the average rating for a given row is equal to the percentage for each of the other rows, where only significant differences at the 5 percent level are reported. For example, for row 2 the recorded " $1,5-9$ " in the column signifies that the percentage for the response in row 2 is significantly different from the percentages for the responses in rows 1 and 5 to 9 . Column 5 reports the results of a t-test of the null hypothesis that the average rating for a given row is equal to 3. Columns (6) and (7) report the average rating for investors with AUM $>\$ 5$ billion (large) and AUM $<\$ 5$ billion (small), respectively. Column (8) reports the results of a t-test of the null hypothesis that the average ratings in Columns (6) and (7) are equal to each other. Column (9) and (10) report the average rating for investors with ESG allocation $>5 \%$ of AUM (high) and ESG allocation $<5 \%$ of AUM (low), respectively. Column (11) reports the results of a t-test of the null hypothesis that the average ratings in Columns (9) and (10) are equal to each other. Columns (12) to (14) report the percentages by geographical regions and the respective tests of the null hypothesis that the percentages in the specified columns are equal to each other. $* * *, * *, *$ denotes significance at the $1 \%, 5 \%$, and $10 \%$ level, respectively. 
Table 11: ESG strategies outlook

Survey responses to question: How important will the following methods of using ESG information in your investment process become in the next 5 years? (Scale: 3 = very important, $2=$ somewhat important, $1=$ not important)

\begin{tabular}{|c|c|c|c|c|c|c|c|c|c|c|c|c|c|c|c|}
\hline & \multirow[t]{3}{*}{$N=309$} & \multicolumn{5}{|c|}{ ALL } & \multicolumn{3}{|c|}{ AUM Size } & \multicolumn{3}{|c|}{ ESG Allocation } & \multicolumn{3}{|c|}{ Region } \\
\hline & & (1) & (2) & (3) & (4) & (5) & (6) & (7) & (8) & (9) & $(10)$ & $(11)$ & $(12)$ & (13) & (14) \\
\hline & & $\begin{array}{l}\% \text { very } \\
\text { important }\end{array}$ & $\begin{array}{c}\% \text { not } \\
\text { important }\end{array}$ & $\begin{array}{c}\text { Average } \\
\text { Rating }\end{array}$ & $\begin{array}{l}\text { Significant } \\
\text { difference } \\
\text { in average } \\
\text { rating vs } \\
\text { rows }\end{array}$ & $\begin{array}{c}\text { H0: } \\
\text { Average } \\
\text { rating = } \\
2\end{array}$ & Large & Small & $\begin{array}{l}\text { Diff } \\
(6)- \\
(7)\end{array}$ & High & Low & $\begin{array}{l}\text { Diff } \\
(9)- \\
(10)\end{array}$ & US & Europe & $\begin{array}{l}\text { Diff } \\
(12)- \\
(13)\end{array}$ \\
\hline 1 & Positive screening & $32.5 \%$ & $28.5 \%$ & 2.04 & 6-9 & & 2.17 & 1.98 & ** & 2.24 & 1.90 & $* * *$ & 2.05 & 2.11 & \\
\hline 2 & Engagement/active ownership & $33.7 \%$ & $31.2 \%$ & 2.02 & $8-9$ & & 2.09 & 1.99 & & 2.33 & 1.81 & $* * *$ & 1.81 & 2.23 & $* * *$ \\
\hline 3 & Negative screening & $29.7 \%$ & $29.8 \%$ & 1.98 & $8-9$ & & 2.06 & 1.94 & & 2.13 & 1.88 & $* * *$ & 1.91 & 2.13 & $* *$ \\
\hline 4 & $\begin{array}{l}\text { Full integration into individual } \\
\text { stock valuation }\end{array}$ & $29.0 \%$ & $31.7 \%$ & 1.98 & $8-9$ & & 2.09 & 1.92 & * & 2.23 & 1.79 & $* * *$ & 1.82 & 2.10 & ** \\
\hline 5 & Thematic investment & $24.8 \%$ & $31.4 \%$ & 1.91 & 1,9 & $*$ & 2.05 & 1.85 & ** & 2.08 & 1.79 & $* * *$ & 1.83 & 2.03 & $*$ \\
\hline 6 & $\begin{array}{l}\text { Relative screening/ best-in-class } \\
\text { screening }\end{array}$ & $24.1 \%$ & $32.5 \%$ & 1.91 & 1,9 & ** & 1.93 & 1.91 & & 2.13 & 1.76 & $* * *$ & 1.76 & 2.01 & ** \\
\hline & investing & $22.7 \%$ & $32.5 \%$ & 1.90 & $1-2,9$ & $* *$ & 1.92 & 1.89 & & 2.06 & 1.79 & $* * *$ & 1.69 & 1.95 & ** \\
\hline 8 & Impact investment & $21.7 \%$ & $41.2 \%$ & 1.81 & $1-4,9$ & $* * *$ & 1.84 & 1.79 & & 1.98 & 1.68 & $* * *$ & 1.62 & 1.90 & $* * *$ \\
\hline 9 & Overlay/portfolio tilt & $12.1 \%$ & $46.0 \%$ & 1.62 & $1-8$ & $* * *$ & 1.67 & 1.60 & & 1.81 & 1.49 & $* * *$ & 1.48 & 1.70 & ** \\
\hline
\end{tabular}

Column 1 (2) reports the percentage of respondents indicating the importance levels of 2 or 3 (1) on a scale of 1 to 3 . Column 3 presents the average rating. Column 4 shows the results of a t-test of the null hypothesis that the average rating for a given row is equal to the percentage for each of the other rows, where only significant differences at the 5 percent level are reported. For example, for row 1 the recorded " $6-9$ " in the column signifies that the percentage for the response in row 2 is significantly different from the percentages for the responses in rows 6 to 9 . Column 5 reports the results of a t-test of the null hypothesis that the average rating for a given row is equal to 3. Columns (6) and (7) report the average rating for investors with AUM $>\$ 5$ billion (large) and AUM $<\$ 5$ billion (small), respectively. Column (8) reports the results of a t-test of the null hypothesis that the average ratings in Columns (6) and (7) are equal to each other. Column (9) and (10) report the average rating for investors with ESG allocation $>5 \%$ of AUM (high) and ESG allocation < 5\% of AUM (low), respectively. Column (11) reports the results of a t-test of the null hypothesis that the average ratings in Columns (9) and (10) are equal to each other. Columns (12) to (14) report the percentages by geographical regions and the respective tests of the null hypothesis that the percentages in the specified columns are equal to each other. $* * *, * *, *$ denotes significance at the $1 \%, 5 \%$, and $10 \%$-level, respectively. 